\title{
Apolipoprotein A-I is a selective target for myeloperoxidase-catalyzed oxidation and functional impairment in subjects with cardiovascular disease
}

\author{
Lemin Zheng, ${ }^{1,2}$ Benedicta Nukuna, ${ }^{1}$ Marie-Luise Brennan, ${ }^{1}$ Mingjiang Sun, ${ }^{1}$ \\ Marlene Goormastic, ${ }^{3}$ Megan Settle, ${ }^{1}$ Dave Schmitt, ${ }^{1}$ Xiaoming Fu, ${ }^{1}$ \\ Leonor Thomson, ${ }^{4}$ Paul L. Fox, 1,5,6 Harry Ischiropoulos, ${ }^{4}$ Jonathan D. Smith, 1,5,6 \\ Michael Kinter, ${ }^{1,2,6}$ and Stanley L. Hazen ${ }^{1,2,3,5}$
}

\begin{abstract}
${ }^{1}$ Department of Cell Biology, Center for Cardiovascular Diagnostics and Prevention, Cleveland Clinic Foundation, Cleveland, Ohio, USA.
${ }^{2}$ Department of Chemistry, Cleveland State University, Cleveland, Ohio, USA. ${ }^{3}$ Departments of Cardiovascular Medicine, Center for Cardiovascular Diagnostics, and Prevention, Cleveland Clinic Foundation, Cleveland, Ohio, USA. ${ }^{4}$ Stokes Research Institute and Department of Biochemistry and Biophysics, Children's Hospital of Philadelphia and The University of Pennsylvania, Philadelphia, Pennsylvania, USA. ${ }^{5}$ Department of Molecular Medicine, Cleveland Clinic Lerner College of Medicine of Case Western Reserve University, Cleveland, Ohio, USA. ${ }^{6}$ Department of Physiology and Biophysics, Case Western Reserve University School of Medicine, Cleveland, Ohio, USA.
\end{abstract}

In recent studies we demonstrated that systemic levels of protein-bound nitrotyrosine $\left(\mathrm{NO}_{2} \mathrm{Tyr}\right)$ and myeloperoxidase (MPO), a protein that catalyzes generation of nitrating oxidants, serve as independent predictors of atherosclerotic risk, burden, and incident cardiac events. We now show both that apolipoprotein A-I (apoA-I), the primary protein constituent of HDL, is a selective target for MPO-catalyzed nitration and chlorination in vivo and that MPO-catalyzed oxidation of HDL and apoA-I results in selective inhibition in ABCA1-dependent cholesterol efflux from macrophages. Dramatic selective enrichment in $\mathrm{NO}_{2} \mathrm{Tyr}$ and chlorotyrosine ( $\mathrm{ClTyr}$ ) content within apoA-I recovered from serum and human atherosclerotic lesions is noted, and analysis of serum from sequential subjects demonstrates that the $\mathrm{NO}_{2} \mathrm{Tyr}$ and ClTyr contents of apoA-I are markedly higher in individuals with cardiovascular disease (CVD). Analysis of circulating HDL further reveals that higher $\mathrm{NO}_{2} \mathrm{Tyr}$ and ClTyr contents of the lipoprotein are each significantly associated with diminished ABCA1-dependent cholesterol efflux capacity of the lipoprotein. MPO as a likely mechanism for oxidative modification of apoA-I in vivo is apparently facilitated by MPO binding to apoA-I, as revealed by cross-immunoprecipitation studies in plasma, recovery of MPO within HDL-like particles isolated from human atheroma, and identification of a probable contact site between the apoA-I moiety of HDL and MPO. To our knowledge, the present results provide the first direct evidence for apoA-I as a selective target for MPO-catalyzed oxidative modification in human atheroma. They also suggest a potential mechanism for MPO-dependent generation of a proatherogenic dysfunctional form of HDL in vivo.

\section{Introduction}

Substantial evidence supports the notion that oxidative processes participate in the pathogenesis of atherosclerotic heart disease (1-5). One such oxidative pathway that appears to be involved is formation of oxidants derived from nitric oxide (NO, nitrogen monoxide) (6-10). NO typically functions as a potent vasodilator and inhibitor of platelet aggregation, leukocyte adhesion, and smooth muscle cell proliferation (11-13). However, under pathological conditions such as during inflammation and cardiovascular disease (CVD), NO may be converted into potent nitrating oxidants

Nonstandard abbreviations used: acetylated LDL (AcLDL); cardiovascular disease (CVD); chlorotyrosine (ClTyr); collision-induced dissociation (CID); diethylenetriaminepentaacetic acid (DTPA); 2-dimensional (2D); immobilized pH gradient (IPG); liquid chromatography (LC); mass spectrometry (MS); nitrotyrosine $\left(\mathrm{NO}_{2} \mathrm{Tyr}\right)$; online electrospray ionization tandem MS (LC/ESI/MS/MS); ox-amino acid (ox-AA); trifluoroacetic acid (TFA).

Conflict of interest: Stanley L. Hazen is named as a co-inventor on pending patents filed by the Cleveland Clinic Foundation that relate to the use of biomarkers for inflammatory and cardiovascular diseases.

Citation for this article: J. Clin. Invest. 114:529-541 (2004). doi:10.1172/JCI200421109. that promote oxidative damage, cell injury, and conversion of LDL, the major carrier of cholesterol in plasma, into an atherogenic form $(9,14)$. Protein-bound nitrotyrosine $\left(\mathrm{NO}_{2} \mathrm{Tyr}\right)$, a posttranslational modification specific for protein oxidation by NO-derived oxidants (15-20), is markedly enriched within human atheroma $(8,21)$. Further, recent clinical studies demonstrate that systemic levels of protein-bound $\mathrm{NO}_{2}$ Tyr serve as an independent predictor of atherosclerotic risk and burden in subjects and are modulated by known CVD risk-reducing therapies such as statins $(10,22)$. Few studies to date have focused on defining the molecular targets of nitration in subjects with CVD, the attendant functional alterations, and the enzymatic participants in nitration.

One potential enzymatic source for generation of NO-derived oxidants within human atheroma is the heme protein myeloperoxidase (MPO). MPO utilizes hydrogen peroxide $\left(\mathrm{H}_{2} \mathrm{O}_{2}\right)$ and a variety of low-molecular weight organic and inorganic substances as substrates to form reactive oxidant species capable of promoting protein halogenation, nitration, and oxidative cross-linking $(4,5)$. For example, MPO directly utilizes both NO (23) and the NO metabolite nitrite $\left(\mathrm{NO}_{2}^{-}\right)$as substrates in vitro $(17-19,24)$ and participates 


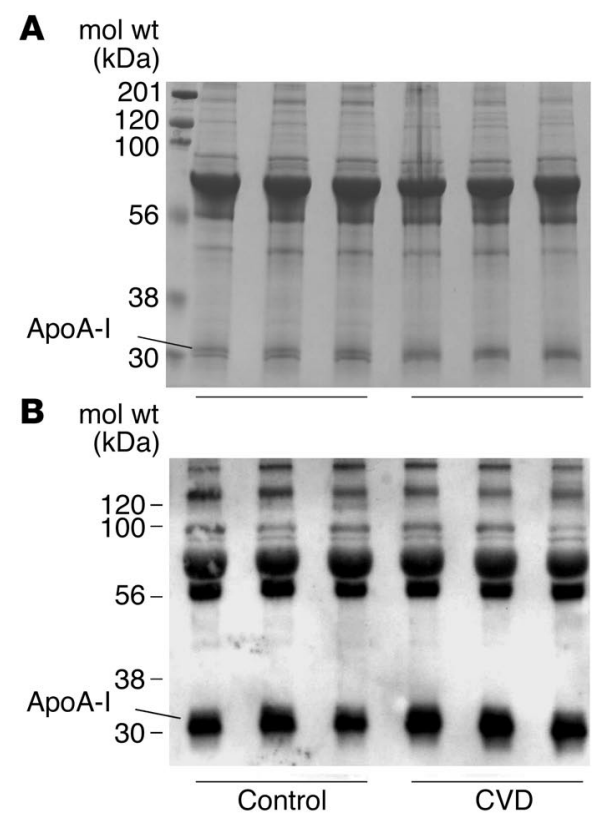

in both protein nitration and initiation of lipid peroxidation in vivo $(17,25-27)$. MPO $(28,29)$, and multiple specific oxidation products formed by the enzyme $(8,16,30,31)$, are markedly enriched within human atherosclerotic lesions. Further, recent clinical studies demonstrate that elevated levels of MPO both are seen in patients with angiographic evidence of CVD (32) and predict incident risks for myocardial infarction, revascularization, and cardiac death in subjects presenting with chest pain or acute coronary syndrome $(33,34)$. Accordingly, defining targets of oxidative modification by MPO- and NO-generated oxidants, and potential functional consequences that result, is of considerable interest.

In the present study we have begun the process of identifying protein targets that are nitrated in serum of subjects with CVD. Early preliminary studies identified enrichment in $\mathrm{NO}_{2}$ Tyr content within apolipoprotein A-I (apoA-I), the major protein constituent within HDL. Further analyses reveal that MPO binds to apoA-I and likely serves as the major enzymatic catalyst for apoA-I nitration in vivo, selectively targeting the lipoprotein for MPOcatalyzed nitration and halogenation within human atheroma. In vitro studies demonstrate that MPO-catalyzed oxidative modification of HDL or apoA-I is accompanied by selective impairment in ABCA1-dependent cholesterol efflux function of the lipoprotein. In vivo evidence for a functional role of MPO- and NO-derived oxidants in the inhibition of apoA-I cholesterol efflux activity in

\section{Figure 2}

Confirmation of apoA-I as a nitrated protein by both 2D SDS-PAGE and anti- $\mathrm{NO}_{2} \mathrm{Tyr}$ affinity chromatography coupled to tandem MS-based sequencing. Plasma from a subject with CVD was loaded onto an affinity matrix composed of immobilized affinity-purified rabbit anti- $\mathrm{NO}_{2} \mathrm{Tyr}$ polyclonal antibodies, washed with high salt, and then eluted with addition of $5 \mathrm{mM}$ free $\mathrm{NO}_{2} \mathrm{Tyr}$, as described in Methods. (A) Demonstration of apoA-I location on 2D SDS-PAGE. Identity of protein was established by tandem MS sequence analysis of peptides (>95\% coverage). (B) The anti- $\mathrm{NO}_{2}$ Tyr eluent ( $5 \mathrm{mM} \mathrm{NO}_{2} \mathrm{Tyr}$ ) was subjected to 2D SDSPAGE, and the presence of apoA-I was confirmed by Western blot analysis. Parallel studies using control nonimmune $\lg G$ as the affinity matrix failed to bind detectable levels of apoA-I (not shown).

\section{Figure 1}

ApoA-I is a preferred target for nitration in serum. Serum samples $(25 \mu \mathrm{g}$ total protein per lane) from 3 healthy controls and 3 subjects with CVD were separated by SDS-PAGE. The gels (12.5\%) were either stained for protein with Coomassie blue (A) or transferred and probed with a mAb specific for protein-bound $\mathrm{NO}_{2} \mathrm{Tyr}(\mathrm{B})$. The apoA-I bands were identified by sequence analysis by tandem mass spectrometry (MS). The disproportionate recognition of the apoA-I band in the Western blot analysis is consistent with an enhanced $\mathrm{NO}_{2}$ Tyr content of that protein.

subjects was obtained by observation of a significant correlation between higher apoA-I $\mathrm{NO}_{2}$ Tyr and chlorotyrosine (ClTyr) content of isolated HDL and diminished ABCA1-dependent cholesterol efflux activity of the lipoprotein. The present study suggests that MPO-apoA-I interactions may play an important role in development of "dysfunctional" or "proinflammatory" HDL and the atherosclerotic phenotype.

\section{Results}

Identification of apoA-I as a nitrated protein in serum. Serum levels of protein-bound $\mathrm{NO}_{2}$ Tyr serve as a predictor of atherosclerotic risk and burden in subjects (10), raising the question of whether nitration of specific proteins might contribute to the atherosclerotic process. As a first step in investigating this question, we sought to determine the identities of nitrated proteins in serum. Samples from patients with CVD and controls were analyzed by SDS-PAGE and visualized by both Western blot analysis using anti- $\mathrm{NO}_{2} \mathrm{Tyr}$ antibodies, and Coomassie blue staining for proteins. Comparison of the pattern of immunoreactivity seen in the Western blot (Figure $1 \mathrm{~B}$ ) versus protein staining (Figure 1A) reveals that not all serum proteins are equally nitrated. An example of a disparity between a modest abundance versus an extensive degree of nitration was reproducibly observed in a $29-\mathrm{kDa}$ protein. This protein band was cut from the Coomassie

mol wt

A $(\mathrm{kDa})$

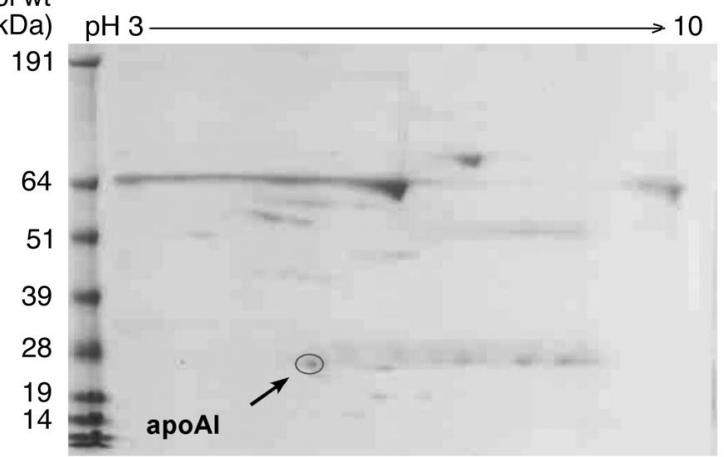

$\mathrm{mol} w \mathrm{t}$

B $(\mathrm{kDa})$

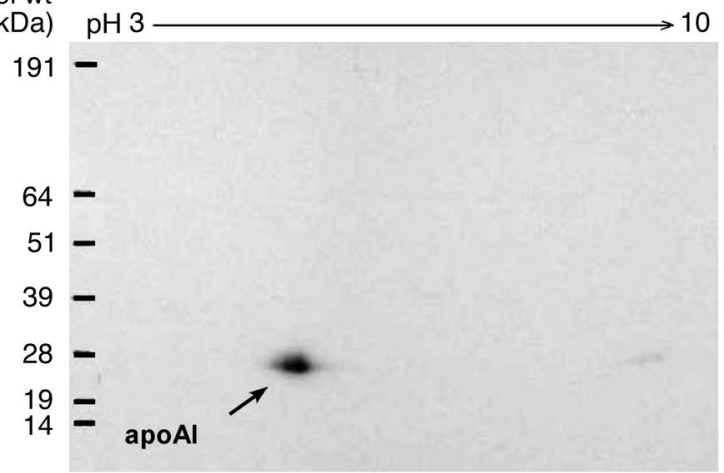


Table 1

Clinical and laboratory characteristics

\begin{tabular}{lccc} 
& & & \\
& Controls $(\boldsymbol{n}=\mathbf{4 4})$ & CVD $(\boldsymbol{n}=\mathbf{4 5})$ & $\boldsymbol{P}$ value \\
Age & $44.3 \pm 11.1$ & $65.6 \pm 8.5$ & $<0.001$ \\
Male (\%) & $24(54.6)$ & $17(37.8)$ & 0.12 \\
Diabetes (\%) & $0(0)$ & $24(53.3)$ & $<0.001$ \\
Hypertension (\%) & $14(31.8)$ & $32(71.1)$ & $<0.001$ \\
Smoking (\%) & $22(50.0)$ & $37(82.2)$ & 0.001 \\
Family hx CVD (\%) & $5(11.4)$ & $19(42.2)$ & 0.001 \\
Hx hyperlipidemia (\%) & $7(15.9)$ & $31(68.9)$ & $<0.001$ \\
Statin use & $0(0)$ & $28(62.2)$ & $<0.001$ \\
TC (mg/dl) & $201 \pm 33$ & $165 \pm 36$ & $<0.001$ \\
HDLc (mg/dl) & $60 \pm 16$ & $42 \pm 15$ & $<0.001$ \\
LDLC (mg/dl) & $120 \pm 34$ & $91 \pm 24$ & $<0.001$ \\
TG (mg/dl) & $108 \pm 54$ & $171 \pm 96$ & $<0.001$ \\
Fasting glucose (mg/dl) & $93 \pm 13$ & $94 \pm 3$ & 0.43 \\
& & & \\
\hline
\end{tabular}

Data are presented as either percentage or mean $\pm \mathrm{SD}$ as indicated. HDLc, HDL cholesterol; Hx, history of; LDLc, LDL cholesterol; TC, total cholesterol; TG, triglyceride.

blue-stained gel, digested with trypsin, and unequivocally identified as apoA-I (National Center for Biotechnology Information accession number 253362) based on the detection and sequencing of more than 30 peptides covering $96 \%$ of the protein sequence. Further confirmation of the identity of apoA-I as a nitrated protein was obtained through passage of serum through a column composed of immobilized antibodies to $\mathrm{NO}_{2} \mathrm{Tyr}$, washing of the column with high salt, and then elution with high salt supplemented with $5 \mathrm{mM} \mathrm{NO}_{2} \mathrm{Tyr}$ (Figure 2). Analysis of samples by 2-dimensional (2D) SDS-PAGE and by sequencing based on capillary liquid chromatography-tandem mass spectrometry (LC-tandem MS) confirmed apoA-I as a recovered protein (>90\% coverage by on-line electrospray ionization tandem MS). Further examination of the anti- $\mathrm{NO}_{2} \mathrm{Tyr}$ column eluent (high salt plus $5 \mathrm{mM} \mathrm{NO}_{2} \mathrm{Tyr}$ ) by 2D SDS-PAGE followed by Western blot analysis using antibodies to apoA-I provided additional complementary evidence of apoA-I as a nitrated protein in vivo (Figure $2 \mathrm{~B}$ ).

Demonstration of apoA-I as a preferred target of nitration and chlorination within serum, as well as in subjects with versus without CVD. Given the plethora of targets within tissues like serum and the relatively short diffusion distance for a reactive nitrogen species in complex biological matrices, the apparent selective nitration of apoA-I among serum proteins strongly suggested the existence of an enzymatic source for NO-derived oxidants in close proximity to the lipoprotein in vivo. One likely candidate was the enzyme MPO, since recent studies have shown that this enzyme can catalyze protein nitration in vivo $(17,25-27)$ and plays a dominant role in generation of NO-derived oxidants under certain circumstances, such as within the extracellular compartment at sites of inflammation (17). In order both to test the hypothesis that MPO serves as a possible enzymatic catalyst for selective apoA-I nitration in vivo, and to quantitatively assess whether apoA-I is nitrated to a greater extent within subjects with CVD, we obtained consent from 45 consecutive patients presenting to a cardiology clinic with documented CVD and 44 healthy control subjects and collected their serum samples for analysis. The contents of both $\mathrm{NO}_{2} \mathrm{Tyr}$ and ClTyr were simultaneously quantified within total serum proteins, isolated apoA-I, and isolated apoB-100 using stable isotope dilution HPLC with on-line electrospray ionization tandem MS (LC/ESI/MS/MS). Table 1 lists the clinical and laboratory char- acteristics of the subjects examined. As anticipated, patients with CVD were more likely to have known CVD risk factors including history of diabetes, hypertension, smoking, family history of CVD, and history of hyperlipidemia. Subjects with CVD also had lower LDL cholesterol levels and were more likely to be on statin therapy, features likely attributable to ascertainment bias from enrollment of CVD subjects in a cardiology clinic.

Consistent with our recent published studies (10), serum $\mathrm{NO}_{2}$ Tyr content was significantly increased approximately 1.5 -fold $(P<0.001)$ in subjects with CVD relative to that of healthy controls (Table 2). Similar results (twofold increase; $P=0.001$ for CVD vs. controls; Table 2) were observed when the $\mathrm{NO}_{2}$ Tyr content of isolated apoB-100, the major protein constituent of LDL and a lipoprotein reported to bind to MPO in vitro $(35,36)$, was analyzed. Remarkably, a 70-fold enrichment in $\mathrm{NO}_{2} \mathrm{Tyr}$ content was noted within serum apoA-I relative to serum total proteins and isolated apoB-100. Moreover, a significant increase in $\mathrm{NO}_{2}$ Tyr content of apoA-I was also noted in serum from CVD versus healthy control subjects $(P=0.005$; Table 2$)$. Parallel analysis of samples for ClTyr content, a protein modification specific for MPO-catalyzed oxidation $(16,17,37,38)$, revealed relatively low levels within total proteins and isolated apoB-100 from serum, compared with over 100-fold enrichment in ClTyr content within isolated apoA-I (Table 2). Further, while trends for increases in ClTyr content within subjects with CVD were noted in total protein and isolated apoB-100, these differences failed to reach statistical significance. In contrast, significant increases in ClTyr content were observed within apoA-I recovered from serum $(P<0.001$; Table 2$)$.

\section{Table 2}

ApoA-I is a preferred target for nitration and chlorination in serum and in CVD

\begin{tabular}{|c|c|c|c|}
\hline \multicolumn{2}{|c|}{$\mathrm{NO}_{2} \mathrm{Tyr}$} & \multicolumn{2}{|c|}{ CITyr } \\
\hline $\begin{array}{c}\text { Median (IQR) } \\
\text { ( } \mu \text { mol oxTyr/ } \\
\text { mol Tyr) }\end{array}$ & $P$ value & $\begin{array}{c}\text { Median (IQR) } \\
\text { (umol oxTyr/ } \\
\text { mol Tyr) }\end{array}$ & $P$ value \\
\hline
\end{tabular}

Serum

$\begin{array}{lcccc}\text { Total protein } & & & & \\ \text { Control } & 6.1(3.9-7.8) & & 1.6(0.6-2.4) & \\ \text { CVD } & 9.0(5.7-12.9) & <0.001 & 1.9(1.3-3.1) & 0.07 \\ \text { ApoB-100 } & & & & \\ \text { Control } & 4.0(1.3-6.9) & & 0.0(0.0-1.9) & \\ \text { CVD } & 8.7(5.2-12.1) & 0.001 & 1.9(0.1-4.0) & 0.24 \\ \text { ApoA-I } & & & & \\ \text { Control } & 438(335-598) & & 186(114-339) & \\ \text { CVD } & 629(431-876) & 0.005 & 500(335-65) & <0.001\end{array}$

Aliquots of serum (100 $\mu$ g protein) from the entire cohort from Table 1 (patients with CVD and healthy control subjects) were either analyzed directly (for total protein) or resolved by SDS-PAGE and transferred to PVDF membranes, and bands corresponding to apoA-I and apoB-100 were visualized, excised, and then analyzed by stable isotope dilution LC/ ESI/MS/MS, as described in Methods. Results shown are for median and interquartile ranges of $\mathrm{NO}_{2}$ Tyr and CITyr contents of total serum protein or the indicated lipoprotein, expressed as the mole ratio of oxidized amino acid to parent amino acid, tyrosine. The $P$ values shown are for comparisons of $\mathrm{NO}_{2}$ Tyr and CITyr content between control and CVD groups within the corresponding indicated protein(s). IQR, interquartile range; oxTyr, oxidized tyrosine. 
Table 3

Relationship between serum total protein and apoA-I $\mathrm{NO}_{2}$ Tyr and CITyr content and CVD prevalence

\begin{tabular}{|c|c|c|c|c|}
\hline & \multicolumn{4}{|c|}{ Frequency of CVD per tertile } \\
\hline & 1 & 2 & 3 & $P$ for trend \\
\hline \multicolumn{5}{|l|}{ Serum } \\
\hline Total protein $\mathrm{NO}_{2} \mathrm{Tyr}$ & $30.8 \%$ & $33.3 \%$ & $69.2 \%$ & 0.005 \\
\hline ApoA-I NO${ }_{2} \mathrm{Tyr}$ & $32.0 \%$ & $44.0 \%$ & $72.0 \%$ & 0.005 \\
\hline Total protein CITyr & $40.0 \%$ & $50.0 \%$ & $58.3 \%$ & 0.20 \\
\hline \multirow[t]{3}{*}{ ApoA-I CITyr } & $20.0 \%$ & $48.0 \%$ & $80.0 \%$ & $<0.001$ \\
\hline & \multicolumn{4}{|c|}{ Odds ratio $(95 \% \mathrm{CI})$ of CVD per tertile } \\
\hline & 1 & 2 & & 3 \\
\hline \multicolumn{5}{|l|}{ Serum } \\
\hline Total protein $\mathrm{NO}_{2} \mathrm{Tyr}$ & 1.0 & $1.1(0.4-$ & & $(1.6-16.4)$ \\
\hline ApoA-I NO${ }_{2} \mathrm{Tyr}$ & 1.0 & $1.7(0.5-$ & & $(1.6-18.4)$ \\
\hline Total protein CITyr & 1.0 & $1.5(0.5-$ & & $(0.7-6.6)$ \\
\hline ApoA-I CITyr & 1.0 & $3.7(1.1-1$ & & $(4.0-64.0)$ \\
\hline
\end{tabular}

Top: Frequencies of CVD prevalence within each tertile of the entire cohort. Bottom: Odds ratios and 95\% confidence intervals for the second and third tertiles, compared with the lowest (first) tertile, as predictors of CVD. $\mathrm{Cl}$, confidence interval.

The relationship between $\mathrm{NO}_{2}$ Tyr and ClTyr levels monitored and the prevalence of CVD was further examined in the entire cohort (patients with CVD plus controls). As shown in Table 3 (top), increasing $\mathrm{NO}_{2}$ Tyr content was associated with increasing frequency of CVD, as monitored in either total serum proteins or isolated apoA-I from serum. Further, comparisons between subjects with higher versus lower levels of $\mathrm{NO}_{2} \mathrm{Tyr}$ (third versus first tertile) demonstrated an approximately fivefold increase in the odds of having CVD, whether total proteins or isolated apoA-I from serum was examined (Table 3, bottom). In contrast, only the ClTyr content of isolated apoA-I, and not ClTyr content of total serum proteins (or apoB-100, not shown), was associated with increasing frequency or odds of CVD within the cohort. Remarkably, subjects possessing a high apoA-I ClTyr content (top tertile) were 16-fold more likely to have CVD than those with low apoA-I ClTyr content (bottom tertile) (Table 3, bottom).

Demonstration of apoA-I as a preferred target of nitration and chlorination within human atherosclerotic lesions. To examine whether the preferential targeting of apoA-I by NO- and MPO-generated oxidants occurred within human atheroma, additional studies were performed examining total proteins, apoB-100, and apoA-I recovered from human aortic tissues. LDL-like and HDL-like particles were isolated from both normal aortic tissues and atherosclerotic tissues by differential buoyant density centrifugation, and then confirmed to be enriched in both cholesterol and the appropriate apolipoprotein preparation by Western analysis using polyclonal antibodies to either apoB-100 or apoA-I, as described in Methods. Figure 3 (left) illustrates the further enrichment of $\mathrm{NO}_{2} \mathrm{Tyr}$ content within HDL-like particles isolated from human atherosclerotic lesions, compared with a comparable amount of isolated HDL from peripheral blood. The majority of apoA-I recovered within HDL-like particles from atherosclerotic lesions was monomeric (Figure 3, center). More quantitative assessments of $\mathrm{NO}_{2}$ Tyr and ClTyr contents of apoA-I recovered from normal aortic and lesion tissues relative to those observed in aortic and lesion total proteins and apoB-100 were obtained by stable isotope dilution LC/ESI/MS/MS analysis, the results of which are shown in Table 4. Of note, the contents of $\mathrm{NO}_{2}$ Tyr and ClTyr within total pro- teins, apoB-100, and apoA-I recovered from normal aortic tissues and human atherosclerotic lesions were higher than those observed in serum (compare Tables 2 and 4), suggesting that protein modification by NO- and MPO-generated oxidants preferentially occurs within the artery wall, particularly within atherosclerotic lesions, compared with the intravascular (blood) compartment. As was observed within serum and the serum-derived isolated lipoproteins, the contents of both $\mathrm{NO}_{2}$ Tyr and ClTyr in lesion apoA-I demonstrated a dramatic selective enrichment relative to those in lesion total proteins and lesion apoB-100 (Table 4). Similarly, higher levels are observed within total proteins and the isolated lipoproteins from diseased versus normal vascular tissues.

Demonstration that MPO binds directly to apoA-I. The selective enrichment of $\mathrm{NO}_{2} \mathrm{Tyr}$ and ClTyr, a specific oxidative modification for $\operatorname{MPO}(16,17,37,38)$, within apoA-I, whether recovered from serum or within human atherosclerotic vessels, suggests a possible (patho)physiologic association between apoA-I and MPO in vivo. Independent support for such an association is the strong and statistically significant correlation $(r=0.58, P<0.001)$ noted between ClTyr and $\mathrm{NO}_{2}$ Tyr contents of apoA-I, consistent with a significant common pathway for formation (i.e., MPO). To directly test the hypothesis that MPO interacts with apoA-I, cross-immunoprecipitation studies were performed within plasma from a healthy donor that was supplemented with purified human MPO. Remarkably, antibodies to apoA-I efficiently pulled down MPO in plasma, and conversely, antibodies to MPO efficiently extracted apoA-I from plasma. Parallel control studies using immobilized nonimmune IgG preparations failed to precipitate either MPO or apoA-I (Figure 4). Further analysis of the proteins recovered from plasma following incubation with immobilized anti-MPO antibodies by SDS-PAGE and Coomassie blue staining revealed that apoA-I was a major protein recovered

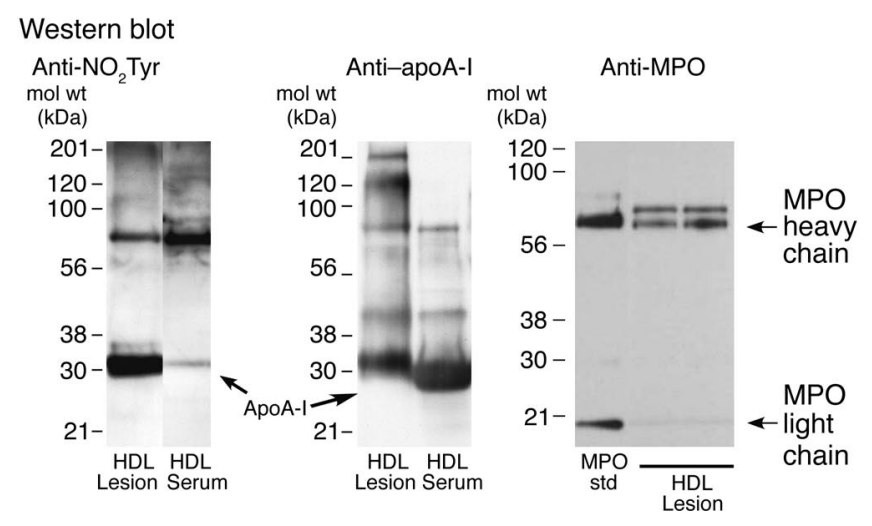

\section{Figure 3}

Demonstration of apoA-I $\mathrm{NO}_{2}$ Tyr and MPO enrichment within HDL-like particles isolated from human atherosclerotic lesions. Left and center: Equal amounts of protein ( $40 \mu \mathrm{g}$ per lane) from either HDL-like particles isolated from human atherosclerotic lesions ( $n=12$ subjects, pooled) or HDL isolated from pooled plasma from healthy donors were analyzed by SDS-PAGE (10-20\% gradient gels), transferred onto PVDF membranes, and probed using antibodies to either anti- $\mathrm{NO}_{2} \mathrm{Tyr}$ (left) or anti-apoA-I (center), and then visualized by brief chemiluminescence exposure, as described in Methods. Right: Isolated human MPO standard (std) or HDL-like particles isolated from human atherosclerotic lesions (40 $\mu \mathrm{g}$ total protein, $n=12$ subjects, pooled) were analyzed by SDS-PAGE (10-20\% gradient gels), transferred onto PVDF membranes, probed using antibodies to human MPO, and then visualized by brief chemiluminescence exposure, as described in Methods. 


\section{Table 4}

ApoA-I is a preferred target for nitration and chlorination within human aortic atherosclerotic lesions

\begin{tabular}{lcccc}
\hline & \multicolumn{2}{c}{ NO ${ }_{2}$ Tyr } & \multicolumn{2}{c}{ CITyr } \\
& $\begin{array}{c}\text { Median (IQR) } \\
\text { ( } \begin{array}{c}\text { mol oxTyr/ } \\
\text { mol Tyr) }\end{array}\end{array}$ & $P$ value & $\begin{array}{c}\text { Median (IQR) } \\
\text { ( } \mu \text { mol oxTyr/ } \\
\text { mol Tyr) }\end{array}$ & $P$ value \\
Normal & & & & \\
Total protein & $55(24-143)$ & & $63(25-128)$ & \\
ApoB-100 & $97(43-222)$ & 0.57 & $49(21-121)$ & 0.93 \\
ApoA-I & $401(185-637)$ & $<0.001$ & $678(299-1,311)$ & $<0.001$ \\
Lesion & & & & \\
Total protein & $108(51-346)$ & & $232(111-431)$ & \\
ApoB-100 & $255(91-480)$ & 0.67 & $318(59-385)$ & 0.92 \\
ApoA-I & 2,340 & $<0.001$ & 3,930 & $<0.001$ \\
& $(1,665-5,050)^{\mathrm{A}}$ & & $(1,679-7,005)^{\mathrm{A}}$ & \\
\hline
\end{tabular}

Specimens of normal human aorta ( $n=10$ subjects) and human aortic atherosclerotic tissues ( $n=22$ subjects) were stripped of adventitia and then pulverized into a powder with a stainless steel mortar and pestle at liquid nitrogen temperatures, and the contents of $\mathrm{NO}_{2} \mathrm{Tyr}$ and $\mathrm{ClTyr}$ were analyzed by stable isotope dilution LC/ESI/MS/MS, as described in Methods. Total protein content of biomarkers was ascertained using powdered human vascular tissue. The contents of oxidized amino acids within normal aortic and atherosclerotic lesion-derived apoB-100 and apoA-I were assessed following isolation of LDL-like and HDL-like particles from powdered vascular tissues by sequential buoyant density centrifugation, further resolving by SDS-PAGE, and transfer to PVDF membranes, and then bands corresponding to apoA-I and apoB-100 were visualized, excised, and analyzed by stable isotope dilution LC/ESI/ MS/MS, as described in Methods. Results shown are for median and interquartile ranges of $\mathrm{NO}_{2} \mathrm{Tyr}$ and $\mathrm{ClTyr}$ contents of normal aortic and lesion total protein or the indicated lipoproteins, expressed as the mole ratio of oxidized to parent amino acid, tyrosine. The $P$ values shown are for comparisons of $\mathrm{NO}_{2} \mathrm{Tyr}$ or $\mathrm{Cl}$ Tyr content in the indicated isolated lipoproteins from human normal aortic and atherosclerotic lesions versus the corresponding content observed in normal or lesion aortic tissue total proteins. ${ }^{A} P<0.001$, lesion apoA-I vs. normal aortic tissue apoA-I.

(Figure 4B, right). Finally, a remarkable finding was that MPO was identified as an HDL-associated protein within human atheroma following the multistep buoyant density isolation procedure for HDLlike particle recovery from atherosclerotic lesions (Figure 3, right). Collectively, these results strongly suggest that MPO directly associates with apoA-I within the artery wall, facilitating selective oxidative modification through reactive halogen and nitrogen species.

The interaction of MPO and HDL was examined more closely using hydrogen/deuterium exchange coupled to MS to identify potential MPO-apoA-I contact(s) sites. The hydrogen/deuterium exchange method is based on monitoring the ability of backbone amide protons to exchange with the solvent as a measure of solvent accessibility - a process that occurs readily at neutral $\mathrm{pH}$, but that can be slowed 10 orders of magnitude at acidic $\mathrm{pH}(\mathrm{pH} 2)(39,40)$. The labile backbone hydrogens are pre-exchanged to deuterium so that the solvent-accessible sites on the protein are labeled in a manner that allows back (off) exchange with hydrogen to be monitored by MS $(39,40)$. When this method is combined with pepsin digestion of the protein and micro-LC-MS analysis, the degree of back exchange can be sensitively and specifically measured within individualized peptic peptides, each of which serves as an intrinsic probe of protein-protein interactions spanning the entire protein sequence. Thus, sites of protein-protein contact, or attendant conformational alterations that alter solvent accessibility during protein-protein interactions, may be sensitively and specifically evaluated.

During reactions of MPO with HDL, we analyzed 22 peptic peptides covering $95 \%$ of apoA-I and found only 1 peptide, corresponding to a portion of helix 8 (A190-L203), that MPO protected from hydrogen/deuterium exchange (Figure 5A, left, spectrum d). For these experiments, exchangeable protons on HDL and MPO were deuterated by separate incubations of each in $\mathrm{D}_{2} \mathrm{O}$ buffer at neutral $\mathrm{pD}$ and $37^{\circ} \mathrm{C}$, followed by mixing of MPO and HDL in the same $\mathrm{D}_{2} \mathrm{O}$ buffer for 1 hour. The reaction mixture was then diluted with more than 20 -fold excess $\mathrm{H}_{2} \mathrm{O}$ buffer $\left(\mathrm{pH} 7.0,37^{\circ} \mathrm{C}\right.$ ) to allow the back (off) exchange ( $t=10$ minutes) of deuterium with protons from solvent-accessible sites on the proteins. Exchange was quenched by acidification and immersion into an ice/methanol bath $\left(\mathrm{pH} 2.5,-10^{\circ} \mathrm{C}\right)$, and then samples were analyzed by pepsin proteolysis and reverse-phase HPLC-tandem MS.

The different spectra shown in Figure 5A (left) show the isotopic cluster of the A190-L203 peptide of apoA-I at various stages in the hydrogen/deuterium exchange experiment. Spectra a and $\mathrm{b}$ contain the peptide isotopic cluster before and after deuterium labeling, respectively, whereas spectra $\mathrm{c}$ and $\mathrm{d}$ contain the deuterium-labeled peptide cluster after back (off) exchange with hydrogen in the absence and presence of MPO binding, respectively. Protection of peptide A190-L203 from the back exchange is seen in the deuterated isotope cluster centered at $m / z 1,578.7$ in the mixed MPO/HDL sample shown (Figure 5A, left, spectrum d). In the absence of MPO (Figure 5A, spectrum c), nearly complete back exchange is observed. For illustrative purposes, a parallel set of data for peptide L159-L170, a negative control peptide whose behavior is representative of all other peptides monitored, is also shown. Note that the leftward shift in isotopic cluster from higher $m / z$ for this peptide during off exchange from $\mathrm{D}_{2} \mathrm{O}$ to $\mathrm{H}_{2} \mathrm{O}$ is complete in the presence of MPO (Figure 5A, right, spectra d and c are comparable), whereas a residual population of the A190-L203 peptides retained a higher $m / z$ during the off exchange experiment in the presence of MPO (Figure 5A, left, spectra $d$ and $c$ are not comparable). Peptide identities were confirmed by sequence analysis, demonstrating incorporation of deuterium into the exchangeable peptide hydrogens, as shown for both deuterium-labeled and unlabeled forms of A190-L203 (Figure 5B). Further confirmation of the apoA-I peptide A190-L203 as a probable MPO-interaction site was obtained in independent hydrogen/deuterium exchange studies monitoring MPO interactions with isolated human apoA-I in lipid disks (reconstituted human apoA-I in 1-palmitoyl, 2-oleoyl, phosphatidylcholine [POPC]; data not shown). Again, with nearly complete peptic peptide mapping ( $>90 \%$ coverage) of apoA-I, peptide A190-L203 was the only one protected from deuterium back exchange in the presence versus the absence of MPO.

Demonstration that exposure of either HDL or apoA-I to (patho)physiologic levels of MPO-generated nitrating or chlorinating oxidants results in selective inhibition in ABCA1-dependent cholesterol efflux from macrophages. We next examined whether exposure of either HDL or apoA-I to physiologic levels of MPO-generated oxidants alters the cholesterol efflux capabilities of the lipoprotein. Both HDL and apoA-I (lipid-free) were individually incubated with the $\mathrm{MPO} / \mathrm{H}_{2} \mathrm{O}_{2} / \mathrm{NO}_{2}{ }^{-}$system (protein nitration conditions), or the $\mathrm{MPO} / \mathrm{H}_{2} \mathrm{O}_{2} / \mathrm{Cl}^{-}$system (protein chlorination conditions), and then both ABCA1-dependent and -independent cholesterol efflux acceptor activities were measured by incubation with cholesterolloaded murine macrophage RAW264.7 cells in the presence and 

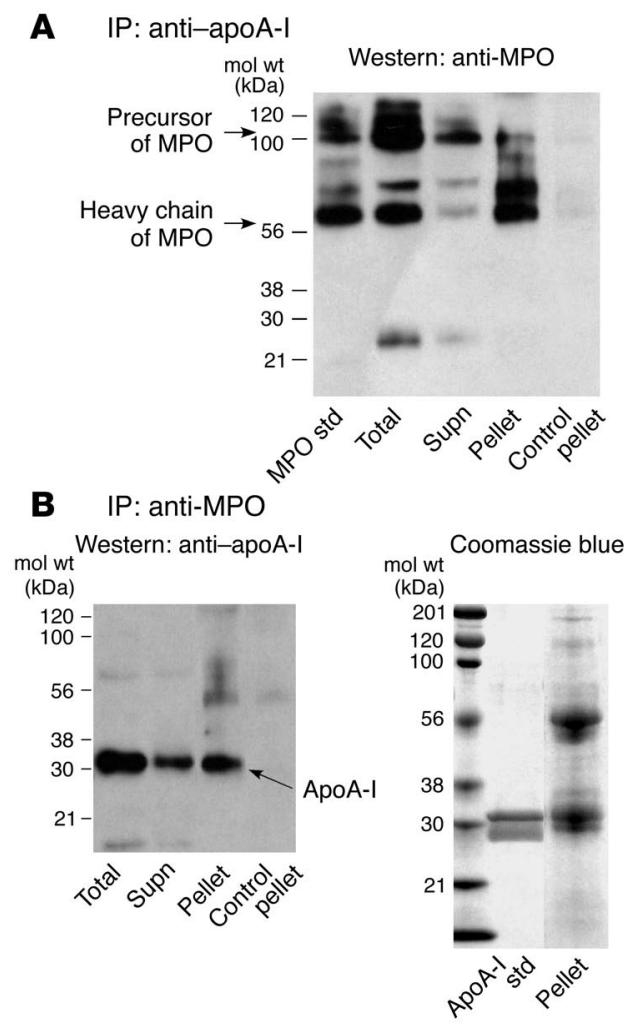

absence of pretreatment with 8-Br-cAMP. In the absence of 8-BrcAMP treatment, RAW264.7 cells do not express an appreciable level of ABCA1, and thus, like fibroblasts from Tangier disease subjects, these cells support cholesterol efflux to HDL via ABCA1independent mechanisms, but almost no cholesterol efflux to apoA-I (41-44). 8-Br-cAMP treatment of RAW264.7 cells induces ABCA1 mRNA and protein, and thus, like fibroblasts from control subjects, these cells support approximately twofold higher levels of cholesterol efflux to HDL and significant levels of cholesterol efflux to lipid-free apoA-I (41, 42, 44, 45). Incubation of either HDL or lipid-free apoA-I with the complete MPO-generated nitrating or chlorinating oxidant systems resulted in significant decreases in ABCA1-dependent cholesterol efflux, without altering ABCA1-independent cholesterol efflux (Figure 6). Analysis of the oxidatively modified forms of HDL by SDS-PAGE and protein silver staining revealed that apoA-I remained predominantly intact, with no evidence of fragmentation and only modest increases in cross-linked forms of apoA-I following exposure to the MPO-generated chlorinating and nitrating oxidants. In all cases, inhibition in ABCA1-dependent cholesterol efflux was only observed in the presence of all components of the complete system (MPO, $\mathrm{H}_{2} \mathrm{O}_{2}$, and cosubstrate $\mathrm{NO}_{2}{ }^{-}$or $\mathrm{Cl}^{-}$), but not in the absence of any one component, or in the presence of hydrogen peroxide alone (data not shown). Remarkably, incubation of HDL with comparable levels of peroxynitrite $(100 \mu \mathrm{M})$ failed to decrease the capacity of HDL to act as a cholesterol acceptor by either ABCA1-dependent or -independent pathways, despite nitration of the apoA-I as monitored by LC/ESI/MS/MS (Figure 6). The loss of ABCA1-dependent efflux for both MPO-modified HDL and isolated apoA-I is consistent with protein modification, rather than lipid modification, causing the effect.

\section{Figure 4}

Coimmunoprecipitation of MPO and apoA-I in plasma. (A) ApoA-I immunoprecipitation (IP) of plasma, followed by MPOWestern blot (10-20\% SDS-PAGE). (B) MPO IP of plasma, followed by apoA-I Western blot (10-20\% SDS-PAGE) (left) or Coomassie blue staining (right). The MPO Western blot (A) was probed with rat anti-human MPO and includes, in the first lane, isolated human MPO as standard. The antiMPO antibody used predominantly recognizes the heavy chain of MPO and thus highlights both heavy chain and precursor protein forms of MPO. The apoA-I Western blot (B) was probed with goat anti-human apoA-I. For each Western blot, the lanes were loaded with $10 \mu \mathrm{g}$ of protein from plasma, the IP supernatant (Supn), and the specific and control immune complexes recovered from the IP pellets, in the indicated sequential order.

Correlation of serum apoA-I content of $\mathrm{NO}_{2} \mathrm{Ty}$ and ClTyr with impairment in ABCA1-dependent cholesterol efflux activity in circulating human $H D L$. We would ideally like to ascertain whether MPO-catalyzed oxidative modification of apoA-I within the artery wall contributes to impairment in cholesterol efflux function of the lipoprotein in atherosclerotic lesions versus normal vessels. However, practical limitations in the amount of diseased and, especially, normal human aortic tissues obtainable precluded this examination. We therefore performed a separate clinical study to explore the in vivo functional relevance of apoA-I oxidative modification to the intrinsic cholesterol efflux activity of the circulating HDL particle. HDL was recovered by immuno-affinity chromatography from sequential subjects, and then ABCA1-dependent cholesterol efflux activity of a fixed mass of apoA-I was determined, and in parallel, the content of apoA-I $\mathrm{NO}_{2} \mathrm{Tyr}$ and ClTyr was measured, as described in Methods. Remarkably, strong and significant inverse correlations were noted for both apoA-I $\mathrm{NO}_{2} \mathrm{Tyr}$ and ClTyr levels, with higher indices of apoA-I oxidative modification correlating with greater impairment in ABCA1-dependent cholesterol efflux activity from cholesterol-laden macrophages (Figure 7).

\section{Discussion}

A growing body of evidence supports a role for inflammation and oxidative processes in CVD pathogenesis $(1-5,46)$. Classically, the "oxidation hypothesis" of atherosclerosis has predominantly focused on the role of oxidation in the modification of LDL and phospholipids, generating proatherogenic species capable of promoting cholesterol deposition, foam cell formation, and proliferation of an inflammatory phenotype. However, over the past few years, evidence has accrued supporting the notion that HDL that has become "dysfunctional" through oxidative modification may also play an important role in the development of atherosclerosis, and that detection of such "proinflammatory" HDL may be a useful marker for gauging susceptibility to atherosclerosis in subjects $(3,47-51)$. Despite these new insights linking oxidation and impaired HDL function with atherosclerosis, direct demonstration of the pathways that participate in HDL oxidation in vivo has not yet been reported.

The present study provides, to our knowledge, the first direct evidence of apoA-I, the major protein constituent of HDL, as a preferential target for nitration and chlorination in the artery wall, as well as a potential mechanism(s) for generation of a proatherogenic form of HDL. The remarkable selective enrichment in apoA-I $\mathrm{NO}_{2} \mathrm{Tyr}$ and ClTyr content observed within both human atherosclerotic lesions and the systemic circulation strongly supports the notion 
A

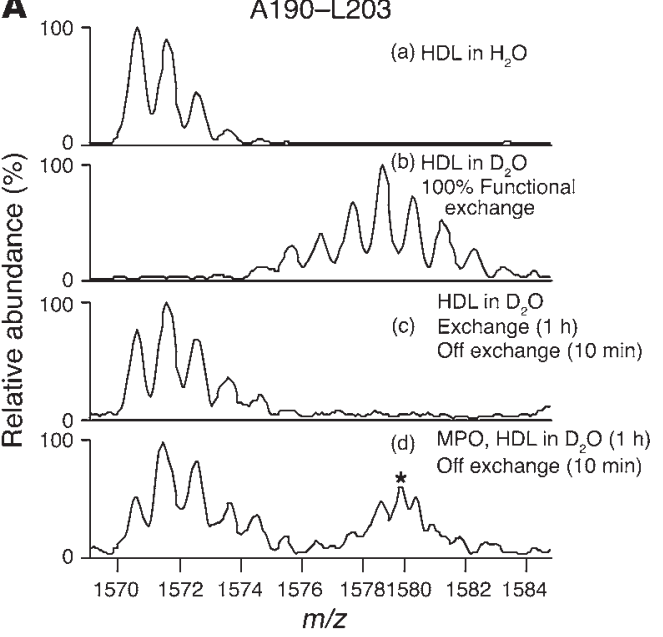

B

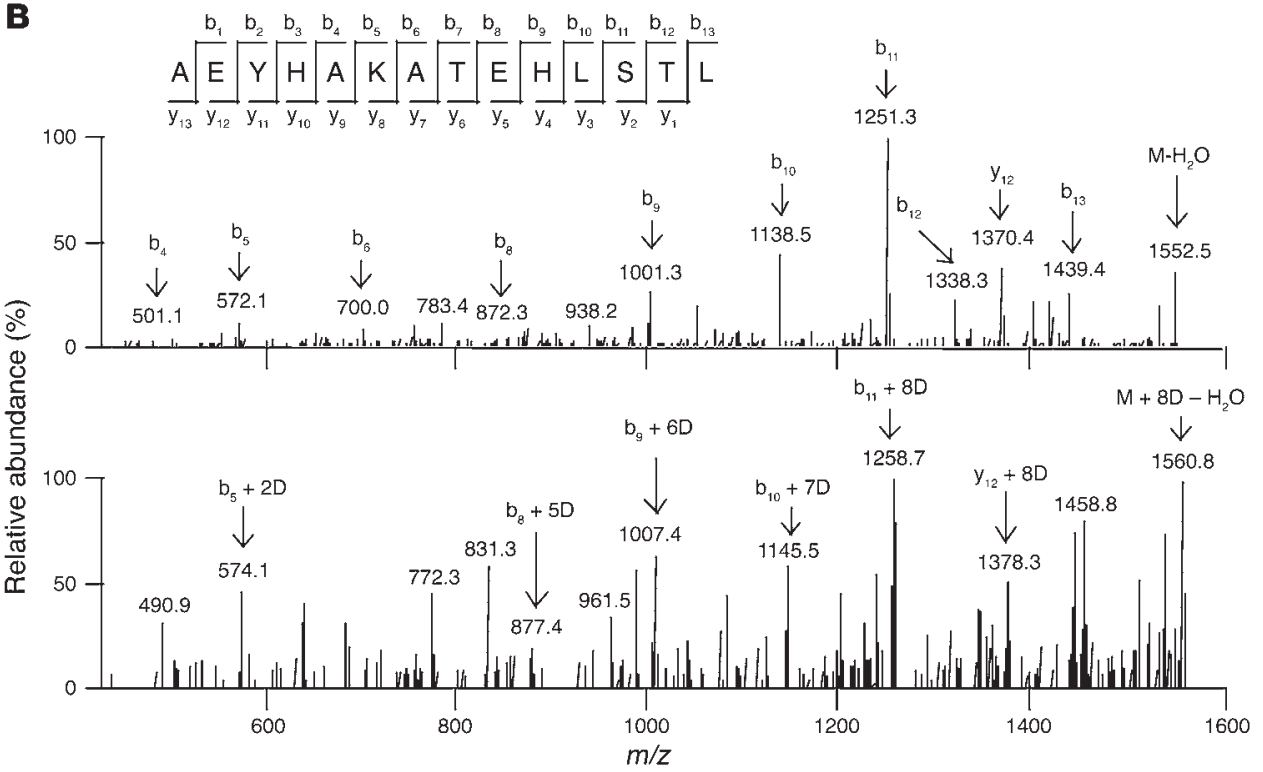

Figure 5

Demonstration of an interaction between MPO and apoA-I using hydrogen/deuterium exchange tandem MS. Exchangeable protons on HDL and MPO were each deuterium-labeled by mixing in $\mathrm{D}_{2} \mathrm{O}$ containing $\mathrm{ND}_{4} \mathrm{OAc}, \mathrm{pD} 7.0$, at room temperature for 1 hour. The deuterated $\mathrm{HDL}$ was combined with either deuterated MPO or additional deuterium buffer and incubated for 1 hour at room temperature to allow binding. Samples were diluted 25-fold into $\mathrm{NH}_{4} \mathrm{OAc}$, pH 7.0, for 10 minutes for back (off) exchange before quenching by rapid cooling and addition of TFA to $\mathrm{pH} 2$. Proteins were digested with immobilized pepsin, and then samples were immediately injected for analysis as described in Methods. The different spectra shown correspond to various stages in the hydrogen/deuterium exchange experiment. (A) ApoA-I isotopic clusters shown are for either the MPO-binding peptide A190-L203 (left) or a negative control peptide, L159-L170 (right). For each, spectra $a$ and $b$ contain peptide isotopic clusters before and after deuterium labeling, respectively. Spectra $\mathrm{c}$ and d contain deuterium-labeled peptide cluster after back (off) exchange with hydrogen in the absence and presence of MPO binding, respectively. The peptide isotopic cluster indicated by the asterisk represents a non-back-exchanged component of the A190-L203 isotope cluster due to inaccessibility of this region of apoA-I to solvent in the presence of MPO. Results shown are representative of 4 independent experiments. (B) Sequence confirmation of the identified peptic peptides was achieved by tandem MS. The collision-induced dissociation spectra and fragmentation analysis of the unlabeled and deuterium-labeled peptic peptide A190-L203 are illustrated.

that NO-derived oxidants and MPO-catalyzed reactions selectively target the lipoprotein for oxidative modification. We observed a combined ox-amino acid (ox-AA) content of 5,500 $\mu \mathrm{mol}$ ox-AA/mol Tyr within lesional apoA-I (Table 4). Given that there are 7 tyrosine residues per apoA-I and up to 4 apoA-I molecules per HDL particle, we calculate that on average, approximately $15 \%$ of the HDL-like particles recovered from human aortic lesions possess at least 1 oxidative modification (i.e., 5.5 ox-AA $/ 10^{3}$ Tyr $\times 7$ Tyr/apoA-I $\times 4$ apoA-I/HDL particle $=15.4 \%$ ). If one looks at the top-quartile values, which demonstrated a combined ox-AA content ranging from 10,000 to $25,000 \mu \mathrm{mol}$ ox-AA/mol Tyr, then a remarkable $28-50 \%$ of lesional HDL particles in this top quartile possess either a ClTyr or an $\mathrm{NO}_{2}$ Tyr residue. Since MPO, $\mathrm{HOCl}$-modified proteins, and apoA-I all colocalize within the protected environment of the subendothelial compartment, it is not hard to imagine that this number may be even higher in some locations. While the selective enrichment of MPO-generated oxidation products was most pronounced within circulating HDL of individuals with CVD and human atherosclerotic lesions, marked enrichment was also noted within apoA-I recovered from both serum of healthy subjects and transplantdonor aortic tissues, suggesting a potential physiologic antiinflammatory/antioxidant role for apoA-I binding of MPO and scavenging of MPO-generated oxidants. Whether the MPO-catalyzed oxidation of apoA-I occurs within the artery wall, or within the circulation, followed by selective deposition of the modified lipoprotein within the artery wall, cannot be determined from the present study. Such high levels of modification, however, strongly argue for the oxidation to occur within a protected environment, such as the subendothelial compartment, where scavengers of MPO-generated oxidants might be more easily depleted.

Another remarkable finding is that both in vitro and in vivo studies demonstrate accompanying functional impairment in ABCA1-dependent cholesterol efflux from cholesterol-laden macrophages with increasing levels of oxidation of apoA-I, suggesting that oxidative processes catalyzed by MPO may participate in the development of "dysfunctional" or "proinflammatory" forms of HDL. The involvement of MPO as an 
A
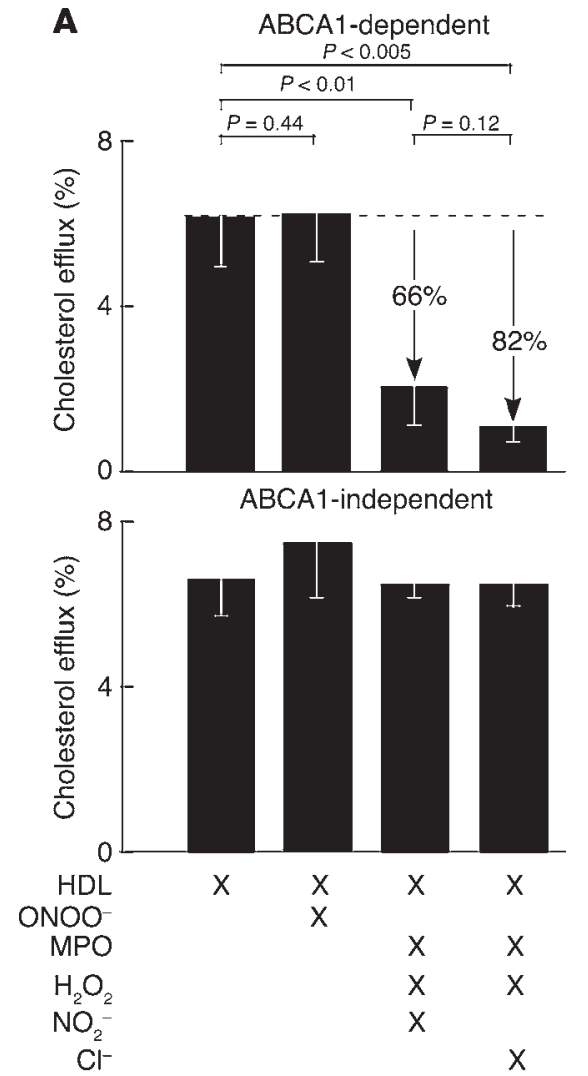

B
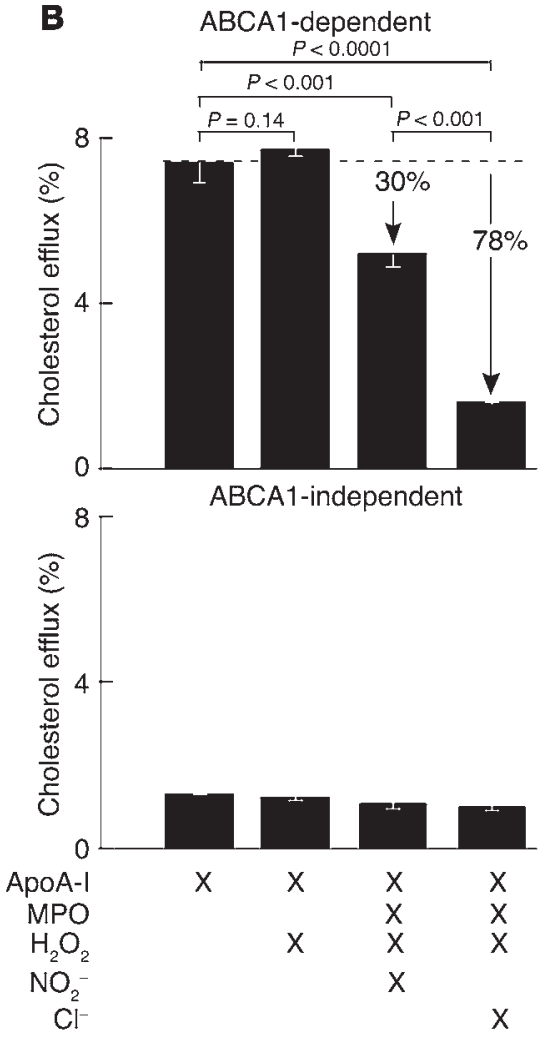

\section{Figure 6}

MPO-generated reactive nitrogen species inhibit ABCA1-dependent cholesterol efflux functions of HDL. HDL (A) and apoA-I (B) were individually modified by $\mathrm{ONOO}^{-}(100 \mu \mathrm{M})$, the $\mathrm{MPO} / \mathrm{H}_{2} \mathrm{O}_{2} / \mathrm{NO}_{2}{ }^{-}$system $\left(100 \mu \mathrm{M} \mathrm{H}_{2} \mathrm{O}_{2}\right)$, or the $\mathrm{MPO} / \mathrm{H}_{2} \mathrm{O}_{2} / \mathrm{Cl}-$ system $\left(100 \mu \mathrm{M} \mathrm{H}_{2} \mathrm{O}_{2}\right)$, as described in Methods. Modified HDL or apoA-I preparations were then incubated with cholesterol-loaded murine macrophage RAW264.7 cells in the presence or absence of 8-Br-cAMP pretreatment, and ABCA1-dependent (top) and -independent (bottom) cholesterol efflux was quantified as described in Methods. Note that MPO-generated nitrating and chlorinating oxidants both selectively inhibited ABCA1-dependent cholesterol efflux. In marked contrast, exposure of HDL or apoA-I to ONOO- failed to influence HDL cholesterol efflux functions of the lipoprotein. enzymatic catalyst in the selective oxidative modification of apoA-I through both nitration and halogenation reactions is supported by multiple lines of evidence, including (a) a dramatic enrichment in both $\mathrm{ClTyr}$, a specific product of $\mathrm{MPO}$, and $\mathrm{NO}_{2} \mathrm{Tyr}$, a product generated by $\mathrm{MPO}$, in apoA-I recovered from both human atheroma and serum; (b) the finding that MPO binds to apoA-I in HDL within plasma and serum, based on both coimmunoprecipitation studies and visualization of a probable site of apoA-I contact with MPO using hydrogen/deuterium exchange MS; (c) the observation that the ClTyr and $\mathrm{NO}_{2}$ Tyr contents of apoA-I show a remarkable statistical correlation $(r=0.58, P<0.001)$, consistent with a significant common enzymatic source; and (d) the copurification of MPO with HDL-like particles recovered from human atherosclerotic lesions.

Several studies have reported functional alterations to HDLmediated cholesterol efflux following oxidative modification in vitro; however, descriptions of the impact of oxidation on cholesterol efflux functions have been contradictory, with decreased (52$54)$, unchanged $(55)$, and increased $(56,57)$ rates of efflux reported. Perhaps the best evidence thus far reported has focused on ex vivo oxidatively cross-linked forms of apoA-I, which are reported to

\section{Figure 7}

Correlation between functional impairment in ABCA1-dependent cholesterol efflux activity and apoA-I content of $\mathrm{NO}_{2} \mathrm{Ty}$ r and CITyr. HDL was immunoprecipitated from serum of consecutive Preventive Cardiology Clinic patients. ABCA1-specific cholesterol efflux activity in $5 \mu \mathrm{g}$ apoA-I was then quantified using cholesterol-laden murine macrophages as described in Methods. In parallel, the content of apoA-I $\mathrm{NO}_{2}$ Tyr (A) and CITyr (B) was determined by stable isotope dilution tandem MS as described in Methods. have enhanced efflux functional capacity in vitro, and the ability to attenuate lesion development when infused in an animal model of atherosclerosis (57). Despite these studies, direct examination of the relevant forms of oxidative modification that are operational
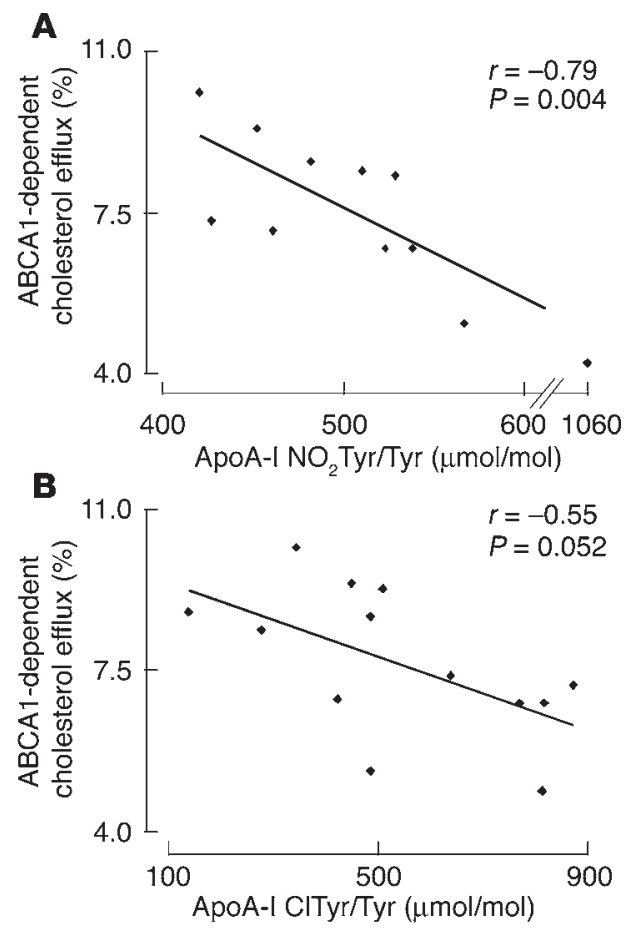
within apoA-I in the artery wall had yet to be reported. Further, while enrichment of $\mathrm{NO}_{2} \mathrm{Tyr}$ and ClTyr in human atherosclerotic lesions was well known from both immunohistochemical and MSbased studies $(8,21,37)$, and colocalization of immunostaining for both apoA-I and HOCl-modified proteins within human atheroma has been reported (58), the present study is the first, to our knowledge, to directly demonstrate MPO-catalyzed oxidative modifications to apoA-I in vivo. The present study is also the first, we believe, to demonstrate (a) that a strong correlation exists between serum apoA-I $\mathrm{NO}_{2} \mathrm{Tyr}$ and ClTyr content and CVD risk, and (b) that a strong correlation exists between serum HDL $\mathrm{NO}_{2}$ Tyr and ClTyr content in subjects and the intrinsic ABCA1mediated cholesterol efflux function of the lipoprotein particle.

Despite the many links between oxidation and atherosclerosis, it should be noted that the oxidation hypothesis of atherogenesis has come under intense scrutiny of late because of the failure of several large-scale prospective antioxidant intervention trials to demonstrate clinical benefit (reviewed in refs. 59-61). While many have interpreted these negative results as an indictment of the oxidation hypothesis, antioxidant action following supplementation in subjects was not directly demonstrated in these trials. Remarkably, many of the oxidation pathways known to be operative in human atheroma, including those mediated by MPO-catalyzed halogenation and NO-derived oxidants, are not efficiently inhibited by $\alpha$-tocopherol (4, 9, 62-64). Further, in many studies "antioxidant" vitamins like $\alpha$-tocopherol and ascorbate have been shown to have no effect on systemic measures of oxidant stress, or even to promote oxidation by either acting as a phase transfer catalyst for radical species (e.g., tocopherol-mediated peroxidation) or allowing redoxactive transition metal ions to catalytically cycle (65-67). Given our recent demonstrations of systemic reductions in total protein $\mathrm{NO}_{2}$ Tyr and ClTyr contents of subjects receiving statin therapy $(10,22)$, it is tempting to speculate that apoA-I $\mathrm{NO}_{2}$ Tyr and ClTyr contents may also serve as clinically useful tools both for CVD risk stratification strategies and for monitoring of the antiinflammatory and antioxidant actions of statins and other therapies. The cross-sectional rather than longitudinal design of the present study is an important limitation. Further evaluation of apoA-I $\mathrm{NO}_{2} \mathrm{Tyr}$ and ClTyr levels as independent additive predictors of future cardiovascular events and outcomes, and as a means of monitoring risk reduction attendant with statin therapy, is warranted.

Epidemiological studies consistently demonstrate an inverse correlation between HDL cholesterol levels and incidence of cardiovascular events. Several functional activities associated with HDL and apoA-I are believed to promote these beneficial effects, including both facilitation of reverse cholesterol transport and additional cardioprotective antioxidant and antiinflammatory functions $(49,68,69)$. A major determinant of plaque progression/regression rate is the balance between cholesterol uptake versus efflux pathways. Enhanced cholesterol efflux from arterial cells, such as with overexpression of human apoA-I in apoE-deficient mice (70), or infusions of recombinant apoA-I forms into subjects, reduces atherosclerotic lesion plaque volume (71). ABCA1 also participates in cholesterol efflux from cells, functioning as a major regulator of macrophage cholesterol efflux and HDL-mediated reverse cholesterol transport (72-76). Upregulation of ABCA1 in liver and macrophages of transgenic mice reduces diet-induced atherosclerosis (77), and bone marrow transplantation studies demonstrate that the selective inactivation of ABCA1 in macrophages markedly increases atherosclerosis and foam cell accumulation in apoE $\mathrm{E}^{-/-}$mice (78).
While initial studies with MPO KO mice demonstrated a modest increase, rather than an anticipated decrease, in lesion development, these studies also revealed significant species differences between rodents and humans with respect to MPO (38). Specifically, while MPO and its oxidation products are enriched in human atheroma, neither MPO nor its specific oxidation products could be demonstrated in mouse aortic lesions, which suggested that human clinical studies were required to determine the role of MPO in human atherosclerosis. The past several years have witnessed an increasing number of clinical and genetic studies in humans that support a role for MPO in atherogenesis. In an analysis of nearly 100 individuals with MPO deficiency, subjects lacking functional peroxidase activity were shown to have a significantly reduced rate of cardiovascular events (79). In several independent genetic studies, a functional polymorphism in the promoter region of the MPO gene that leads to decreased expression has been associated with significant cardioprotective effects in subjects harboring the mutation (80-82). Plasma, serum, and leukocyte MPO levels have now been associated with angiographic evidence of coronary artery disease (32); incident risk of myocardial infarction, death, and need for revascularization $(33,34)$; and enhanced endothelial dysfunction (83). The observed selective targeting of apoA-I for oxidative modification by MPO in vivo, and the apparent accompanying functional impairment in ABCA1-dependent cholesterol efflux function of the lipoprotein, both serve to further suggest that development of an inhibitor of MPO may be of clinical benefit. Alternatively, it is tempting to speculate that the potential apoA-I binding site for MPO identified by the hydrogen/deuterium exchange studies may represent a unique therapeutic target for disrupting aberrant MPO activity in CVD subjects without interfering in needed actions of the enzyme, such as innate host defenses.

\section{Methods}

Materials. L- $\left[{ }^{13} \mathrm{C}_{6}\right]$ tyrosine and L- $\left[{ }^{13} \mathrm{C}_{9},{ }^{15} \mathrm{~N}_{1}\right]$ tyrosine were purchased from Cambridge Isotope Laboratories Inc. (Andover, Massachusetts, USA). Tissue culture media and additives were purchased from Life Technologies Inc. (Gaithersburg, Maryland, USA). RAW264.7 cells were obtained from the American Type Culture Collection (Rockville, Maryland, USA). $\left[{ }^{3} \mathrm{H}\right]$ Cholesterol was obtained from Amersham Biosciences (Piscataway, New Jersey, USA), and resuspended in ethanol prior to use. All other reagents were obtained from Sigma-Aldrich (St. Louis, Missouri, USA) unless otherwise specified.

General procedures. Peroxynitrite was synthesized and quantified as previously described (7). L-3- $\left[{ }^{13} \mathrm{C}_{6}\right] \mathrm{NO}_{2}$ Tyr was synthesized from L- $\left[{ }^{[3} \mathrm{C}_{6}\right]$ tyrosine and peroxynitrite, and isolated by reverse-phase HPLC to remove residual $\mathrm{NO}_{2}^{-}$prior to use (20). Protein content was determined by the Markwellmodified Lowry protein assay (84) with BSA as standard. The concentration of reagent $\mathrm{H}_{2} \mathrm{O}_{2}$ was determined spectrophotometrically $\left(\varepsilon_{240}=39.4 \mathrm{M}^{-1} \mathrm{~cm}^{-1}\right.$; ref. 85). MPO was initially purified from detergent extracts of human leukocytes by sequential lectin affinity and gel filtration chromatography as described by Rakita et al. (86), and then trace levels of contaminating eosinophil peroxidase were removed by passage over a sulphopropyl Sephadex column (87). Purity of isolated MPO was established by demonstration of an $R Z$ greater than $0.84\left(\mathrm{~A}_{430} / \mathrm{A}_{280}\right)$, SDS-PAGE analysis with Coomassie blue staining, and in-gel tetramethylbenzidine peroxidase staining (88). Enzyme concentration was determined spectrophotometrically using an extinction coefficient of $89,000 \mathrm{M}^{-1} \mathrm{~cm}^{-1}$ per heme of MPO (89). Delipidated and purified apoA-I was purchased from BIODESIGN International (Saco, Maine, USA) and used without further purification following demonstration of purity by SDS-PAGE and silver-stain analysis, and demonstration of lack 
of significant FFAs by HPLC with on-line tandem MS analysis (25). LDL $(1.019<d<1.063 \mathrm{~g} / \mathrm{ml}$ fraction) and $\operatorname{HDL}(1.063<d<1.21 \mathrm{~g} / \mathrm{ml}$ fraction $)$ were isolated from fresh plasma by sequential ultracentrifugation (90). Final preparations were extensively dialyzed against $50 \mathrm{mM}$ sodium phosphate $\mathrm{pH}$ 7.0, $200 \mu \mathrm{M}$ diethylenetriaminepentaacetic acid (DTPA) and stored under $\mathrm{N}_{2}$ until use. LDL was acetylated with acetic acid anhydride (91). $\mathrm{NO}_{2} \mathrm{Tyr}$ immunostaining was performed as previously described (92). Specificity of immunostaining for $\mathrm{NO}_{2}$ Tyr was confirmed by loss of staining (a) in competition studies with $10 \mathrm{mM} \mathrm{NO}_{2}$ Tyr present during antibody-antigen incubations, and (b) upon reduction of sample with dithionite.

Clinical specimens: serum. For studies involving MS-dependent quantification of serum total protein, apoA-I, and apoB-100 contents of $\mathrm{NO}_{2} \mathrm{Tyr}$ and ClTyr, 45 sequential patients with CVD receiving care from the Preventive Cardiology Clinic of the Cleveland Clinic Foundation and 44 healthy volunteers responding to advertisements were enrolled. CVD was defined clinically as coronary artery disease, peripheral arterial disease, or cerebral vascular disease. Subjects with CVD were stable and without cardiac symptoms. Patients who had experienced a myocardial infarction or stroke within 1 month preceding enrollment were ineligible. Studies correlating HDL levels of $\mathrm{NO}_{2}$ Tyr and ClTyr with ABCA1-dependent cholesterol efflux activities were performed on a separate sequential set of 13 subjects without known CVD who were receiving care from the Preventive Cardiology Clinic. All participants gave written informed consent, and the Institutional Review Board of the Cleveland Clinic Foundation approved the study protocol. Clinical investigations were conducted in accordance with the Declaration of Helsinki principles. A medical history and record review was performed to define coronary risk factors, including diabetes mellitus (defined by fasting blood glucose $>125 \mathrm{mg} / \mathrm{dl}$ or hypoglycemic medications), hypertension (blood pressure $>140 / 90$ or antihypertensive medications in the absence of known cardiac disease), family history of premature coronary heart disease (first-degree relative with coronary heart disease prior to age 60 by subject report), history of hypercholesterolemia (fasting LDL cholesterol $>160 \mathrm{mg} / \mathrm{dl}$ or lipid-lowering medications in the absence of known cardiac disease), and cigarette smoking (any smoking within 1 year of the study). A fasting blood sample was obtained using a serum-separator tube. Serum was isolated, and aliquots were placed into cryovials supplemented with antioxidant cocktail composed of butylated hydroxytoluene (100 $\mu \mathrm{M}$ final) and DTPA ( $2 \mathrm{mM}$ final, $\mathrm{pH} 7.0)$, covered in argon, and snap-frozen at $-80^{\circ} \mathrm{C}$ until time of analysis.

Immuno-affinity purification of nitrated proteins. An ImmunoPure Protein A Orientation Kit (Pierce Biotechnology Inc., Rockford, Illinois, USA) was used to affinity-purify nitrated proteins from albumin/IgG-depleted serum. Briefly, human serum ( $45 \mu \mathrm{l}$ ) was depleted of albumin and IgG using the ProteoPrep Albumin Depletion Kit (Sigma-Aldrich) as recommended by the manufacturer. Affinity-purified anti- $\mathrm{NO}_{2} \mathrm{Tyr}$ antibody raised against a synthetic octapeptide (Cys-Gly- $\mathrm{NO}_{2}$ Tyr-Gly-Gly-Gly-NO 2 Tyr-Gly) was bound to protein A and cross-linked with dimethylpimelimidate. The albumin/IgGdepleted patient serum was diluted in $0.15 \mathrm{M} \mathrm{NaCl}, 0.1 \mathrm{M}$ phosphate, $\mathrm{pH}$ 7.2 , and applied to the column. Unbound protein fractions were eluted with $20 \mathrm{ml}$ of PBS and $10 \mathrm{ml}$ of $0.5 \mathrm{M} \mathrm{NaCl}$. The bound proteins were eluted with $5 \mathrm{mM} 3-\mathrm{NO}_{2}$ Tyr in $0.5 \mathrm{M} \mathrm{NaCl}$. The bound fractions were concentrated using Centriprep filter devices (YM-10; Millipore Corp., Billerica, Massachusetts, USA), dialyzed against $0.1 \mathrm{M}$ urea, and dried down to a small volume using a SpeedVac Concentrator (Savant Instruments Inc., Holbrook, New York, USA). Protein in the fractions was monitored with the bicinchoninic acid assay (Pierce Biotechnology Inc.), using BSA as standard.

$2 D S D S-P A G E$. After dialysis, approximately $50 \mu \mathrm{g}$ of protein was added to $155 \mu \mathrm{l}$ sample rehydration buffer and absorbed overnight onto $7-\mathrm{cm} \mathrm{pH}$ 3-10 nonlinear immobilized pH gradient (IPG) ZOOM strips (Invitrogen Corp., Carlsbad, California, USA). Isoelectric focusing was carried out using the ZOOM IPGRunner system (Invitrogen Corp.) and the Bio-Rad 3,000-V power supply (Bio-Rad Laboratories, Hercules, California, USA) using the following voltage step protocol: $100 \mathrm{~V}$ for 30 minutes, $200 \mathrm{~V}$ for 20 minutes, $450 \mathrm{~V}$ for 15 minutes, $750 \mathrm{~V}$ for 15 minutes, and 2,000 V for 30 minutes. For the second dimension, focused IPG strips were equilibrated in NuPAGE LDS sample buffer (Invitrogen Corp.) in the presence of NuPAGE Sample Reducing Agent (Invitrogen Corp.) for 15 minutes, and further incubated in LDS sample buffer in the presence of $125 \mathrm{mM}$ iodoacetamide for 15 minutes. The strips were placed on 4-12\% Bis-Tris gels and embedded in $0.5 \%$ agarose (wt $/ \mathrm{vol})$. The gels were stained for protein using either colloidal blue or silver staining. For immunoblotting, gels were transferred to $0.2-\mu \mathrm{m}$ Immun-Blot PVDF membranes (Bio-Rad).

Clinical specimens: tissue. LDL-like and HDL-like particles were isolated from atherosclerotic lesions from aortae and femoral artery tissues obtained at autopsy (tissue harvest within 10 hours of death). Control studies to confirm that postmortem artifacts were not significant used vascular tissues $(n=5)$ obtained fresh at the time of vascular surgery. Normal human aortic tissues were obtained from transplant donors. All tissues were immediately rinsed in ice-cold PBS supplemented with $100 \mu \mathrm{M}$ DTPA and immediately frozen in buffer A (65 mM sodium phosphate, $\mathrm{pH} 7.4,100 \mu \mathrm{M}$ DTPA, 100 $\mu \mathrm{M}$ butylated hydroxytoluene), under $\mathrm{N}_{2}$ at $-80^{\circ} \mathrm{C}$ until analysis.

Isolation and characterization of $L D L$ - and $H D L$-like particles from normal human aortic tissues and human atherosclerotic lesions. LDL- and HDL-like particles were isolated from fatty streaks and intermediate lesions of human thoracic aortae by sequential density ultracentrifugation $(d=1.019-1.070 \mathrm{~g} / \mathrm{ml}$ fraction for "lesion LDL," $1.063-1.21 \mathrm{~g} / \mathrm{ml}$ fraction for "lesion HDL") using a modification of the method of Steinbrecher and Lougheed (93) as previously described (94). "Control aortic LDL-like" and "control aortic HDL-like" particles were similarly isolated from residual aortic tissues free of visible atherosclerotic plaque, obtained from transplant donors. A metal chelator (100 $\mathrm{MM}$ DTPA), an MPO inhibitor (10 mM 3-aminotriazole), and a protease cocktail composed of PMSF and Sigma-Aldrich protease inhibitor cocktail (catalog no. P8340) were included in all solutions used for lipoprotein isolation. Control aortic and lesion LDL and HDL were subjected to SDS-PAGE (95) with Western blot analysis using either a rabbit anti-human apoB-100 antiserum (37) or goat anti-human apoA-I (BIODESIGN International). Analysis of control aortic LDL-like and lesion LDL-like particles with polyclonal antibody to apoB-100 detected a protein of $500 \mathrm{kDa}$, the mass of intact apoB-100. As previously noted (94), both aggregated/cross-linked and lower-molecular mass forms of immunoreactive protein were also present in LDL-like particles isolated from vascular tissues. Similar Western analyses were performed on control aortic HDL-like and lesion HDL-like particles using antibodies to apoA-I, and they confirmed the presence of apoA-I. Analysis of control aortic LDL-like and lesion LDL-like particles by high-resolution size exclusion chromatography (tandem Superose 6 and 12 columns; Pharmacia LKB Biotechnology, Uppsala, Sweden) demonstrated that immunoreactive apoB-100, total cholesterol, and the majority of protein mass exhibited an apparent relative molecular mass similar to that of LDL isolated from plasma. Identity of apoA-I as a major protein constituent present in control aortic HDL-like and lesion HDL-like particle preparations was also achieved by tandem MS sequence analysis following excision from Coomassie blue-stained SDS-PAGE gels.

Several control experiments indicated that postmortem changes were unlikely to contribute to apoA-I nitration and chlorination. First, control studies were performed on fresh arterial tissues harvested at the time of vascular surgery (for lesion) or organ harvest for transplantation (for nor$\mathrm{mal} /$ nonlesion arterial tissues). Comparable levels of $\mathrm{NO}_{2} \mathrm{Tyr}$ and ClTyr were noted within these freshly harvested vascular tissues, compared with those obtained at autopsy. Second, following generation of powdered aortic tissues using a stainless steel mortar and pestle at liquid nitrogen 
temperatures, incubation of aortic tissue powder (suspended in PBS) with MPO (100 nM) for 10 hours at room temperature failed to increase levels of $\mathrm{NO}_{2} \mathrm{Tyr}$ or ClTyr, as monitored by both MS and SDS-PAGE and Western analyses (for $\mathrm{NO}_{2}$ Tyr). Third, control studies demonstrated no significant formation of $3-\left[{ }^{13} \mathrm{C}_{6}\right] \mathrm{ClTyr}$ or $3-\left[{ }^{13} \mathrm{C}_{6}\right] \mathrm{NO}_{2} \mathrm{Tyr}$ in the above aortic tissue powder/MPO mixtures supplemented with L- $\left[{ }^{13} \mathrm{C}_{6}\right]$ tyrosine, incubated at room temperature for 10 hours, and then subjected to MS analysis.

Coimmunoprecipitation study. Human MPO $(67 \mu \mathrm{g})$ was added to $450 \mu \mathrm{l}$ of human plasma from a normal healthy donor. Aliquots $(75 \mu \mathrm{l}$ each) were used for immunoprecipitation studies with the indicated IgG by first mixing with $20 \mu$ l of goat anti-human apoA-I (BIODESIGN International), rat anti-human MPO (DAKO Corp., Carpinteria, California, USA), or nonimmune mouse IgG as a control. Individual mixtures were then diluted with 0.4 $\mathrm{ml} \mathrm{PBS}$ and incubated with $80 \mu \mathrm{l}$ of protein G-Sepharose slurry (Pierce Biotechnology Inc.). The antibody-antigen complexes were pelleted by centrifugation, and the supernatant was removed and saved. After washing, immune complexes in the pellets were recovered from the protein G-Sepharose beads.

Hydrogen/deuterium exchange MS. Separate aliquots of HDL (85 $\mu \mathrm{g}$ protein) and human MPO $(21 \mu \mathrm{g})$ were deuterium-labeled by mixing with 50 $\mu \mathrm{l}$ of $\mathrm{D}_{2} \mathrm{O}$ containing $50 \mathrm{mM} \mathrm{ND}_{4} \mathrm{OAc}, \mathrm{pD} 7.0$, at room temperature for 1 hour. The deuterated HDL was combined with either deuterated MPO or additional deuterium buffer and incubated for 1 hour at room temperature to allow binding. The combined HDL/MPO and the apoA-I-alone samples were concentrated to $10 \mu \mathrm{l}$ by centrifugation through a $10-\mathrm{kDa}$-molecularweight cutoff filter. The retentate was subsequently diluted to $200 \mu \mathrm{l}$ with $50 \mathrm{mM} \mathrm{NH}_{4} \mathrm{OAc}, \mathrm{pH}$ 7.0, for 10 minutes for back (off) exchange before quenching by rapid cooling in ice/methanol bath and addition of $10 \mu 110 \%$ triflouroacetic acid (TFA) to reduce the $\mathrm{pH}$. Proteins were digested with immobilized pepsin that had been prewashed with ice-cold $0.1 \%$ TFA. The pepsin digestion was carried out for 5 minutes and immediately filtered to remove the residual pepsin beads, and then samples were immediately injected for analysis by HPLC-MS/MS. A $1 \mathrm{~mm} \times 3 \mathrm{~cm}$ C18 reverse-phase column (Grace Vydac, Hesperia, California, USA) was used to fractionate peptides. The injector, analytical column, and tubings were all maintained at $0^{\circ} \mathrm{C}$ by immersion in ice/water bath during analysis to minimize back exchange. An aliquot of the sample was injected using a prechilled syringe. Peptides were eluted with a linear gradient of $2-80 \%$ acetonitrile in $0.05 \%$ TFA over 10 minutes. A Finnigan LCQ Deca ion trap mass spectrometer (Thermo-Electron Corp., San Jose, California, USA) was used to record full-scan spectra containing well-resolved isotopic peaks for the respective peptides, as well as collision-induced dissociation (CID) spectra.

$H D L$ and apoA-I nitration and chlorination in vitro. HDL and apoA-I modifications were carried out in $50 \mathrm{mM}$ phosphate buffer, $\mathrm{pH}$ 7.0, containing 100 $\mu \mathrm{M}$ DTPA, $1 \mathrm{mg} / \mathrm{ml}$ HDL protein, $57 \mathrm{pM} \mathrm{MPO}$, and either $100 \mu \mathrm{M}$ nitrite (for the nitration reactions) or $100 \mathrm{mM}$ chloride (for the chlorination reactions). Hydrogen peroxide ( $100 \mu \mathrm{M}$ final) was added to initiate reactions. Peroxynitrite $(100 \mu \mathrm{M})$ was added as a rapid single-bolus addition where specified.

Cholesterol efflux studies. Cholesterol efflux experiments were performed according to established procedures $(96,97)$. Briefly, subconfluent RAW264.7 cells in 24-well dishes were cholesterol-loaded and labeled overnight in $0.5 \mathrm{ml}$ of DGGB (DMEM supplemented with $50 \mathrm{mM}$ glucose, $2 \mathrm{mM}$ glutamine, and $0.2 \% \mathrm{BSA}$ ) containing $\left[{ }^{3} \mathrm{H}\right]$-cholesterol-labeled acetylated LDL (AcLDL). To prepare $\left[{ }^{3} \mathrm{H}\right]$-cholesterol-labeled AcLDL, $\left[{ }^{3} \mathrm{H}\right]$-cholesterol was incubated for 30 minutes at $37^{\circ} \mathrm{C}$ with the AcLDL and diluted with DGGB to yield a final concentration of $50 \mu \mathrm{g} / \mathrm{ml}$ AcLDL with $0.33 \mu \mathrm{Ci} / \mathrm{ml}$ $\left[{ }^{3} \mathrm{H}\right]$-cholesterol. The day after labeling, the cells were washed 3 times in PBS, $0.2 \%$ BSA and incubated with $0.5 \mathrm{ml}$ of DGGB with or without $0.3 \mathrm{mM}$ 8-Br-cAMP (used to induce ABCA1) for 16 hours. Cholesterol efflux to HDL or apoA-I was measured after 4 hours of incubation in $0.5 \mathrm{ml}$ DGGB in the presence or absence of 8-Br-cAMP. Radioactivity of a $100-\mu \mathrm{l}$ aliquot of medium and of a hexane/isopropanol (3:2, vol/vol) extract from the cells was determined. The percentage cholesterol efflux was calculated as the radioactivity in the medium divided by the total radioactivity (medium plus cells). Studies comparing ABCA1-dependent cholesterol efflux activity versus apoA-I $\mathrm{NO}_{2}$ Tyr and ClTyr contents of HDL were performed on HDL recovered from aliquots of serum using affinity-purified anti-HDL IgY gel (GenWay Biotech Inc., San Diego, California, USA). To ensure that comparable mass of apoA-I was applied to cells in experiments evaluating ABCA1-dependent efflux versus apoA-I $\mathrm{NO}_{2}$ Tyr and ClTyr levels (Figure 7), SDS-PAGE analysis with Coomassie blue staining of the anti-HDL precipitates was performed, revealing that more than $90 \%$ of the protein recovered was apoA-I. Individual subjects' serum apoA-I $\mathrm{NO}_{2} \mathrm{Tyr}$ and ClTyr contents were measured in parallel following SDS-PAGE analysis of lipoprotein recovered from immobilized anti-HDL IgY gel, transfer to PVDF, staining, and excision of the apoA-I band, followed by stable isotope dilution tandem MS as described below.

Protein identification by MS. Protein identifications were carried out as previously described $(96,97)$. Briefly, bands were cut from Coomassie blue-stained SDS-PAGE gels, reduced with DTT, and alkylated with iodoacetamide. Protein was then digested in-gel by addition of trypsin, and peptides were extracted and then analyzed by capillary column HPLCtandem MS on a Finnigan LCQ Deca ion trap mass spectrometer system (Thermo-Electron Corp.) equipped with a nanospray ionization source at a flow rate of $200 \mathrm{nl} / \mathrm{min}$. The peptides in the digest were separated by reverse-phase capillary HPLC using a $50-\mu \mathrm{m}$-i.d. column with a $10-\mu \mathrm{m}$ tip (New Objective Inc., Woburn, Massachusetts, USA). The column was packed with approximately $6 \mathrm{~cm}$ of $\mathrm{C} 18$ packing material (Phenomenex, Torrance, California, USA) and eluted using a 45-minute gradient of increasing acetonitrile $(2-70 \%)$ in $50 \mathrm{mM}$ acetic acid. Protein identification was performed using a data-dependent analysis that acquired both mass spectra and CID spectra in a single run $(96,97)$. The search programs SEQUEST (Thermo-Electron Corp.) and Mascot (Matrix Science Ltd., London, United Kingdom) were used for protein identifications. Manual sequence analyses were performed on select deuterium-enriched peptides during hydrogen/deuterium exchange MS.

$\mathrm{NO}_{2}$ Tyr and ClTyr analyses. Protein-bound $\mathrm{NO}_{2} \mathrm{Tyr}$ and ClTyr were quantified by stable isotope dilution LC-tandem MS (17) on a triple quadrupole mass spectrometer (API 4000; Applied Biosystems, Foster City, California, USA) interfaced to an Aria LX Series HPLC multiplexing system (Cohesive Technologies Inc., Franklin, Massachusetts, USA). Synthetic $\left[{ }^{13} \mathrm{C}_{6}\right]$-labeled standards were added to samples (aliquots of serum, tissue/lesion homogenates, or bands visualized on PVDF membranes by colloidal blue stain and then excised) and used as internal standards for quantification of natural-abundance analytes. Simultaneously, a universal labeled precursor amino acid, $\left[{ }^{13} \mathrm{C}_{9},{ }^{15} \mathrm{~N}_{1}\right]$ tyrosine, was added. Proteins were hydrolyzed under argon atmosphere in methane sulfonic acid, and then samples were passed over mini solid-phase C18 extraction columns (Supelclean DSC-18LT minicolumn; 3 ml; Supelco, Bellefone, Pennsylvania, USA) prior to MS analysis. Results are normalized to the content of the precursor amino acid tyrosine, which was monitored within the same injection. Intrapreparative formation of both nitro $\left[{ }^{13} \mathrm{C} 9,{ }^{15} \mathrm{~N}\right]$ tyrosine and chloro $\left[{ }^{13} \mathrm{C}_{9},{ }^{15} \mathrm{~N}\right]$ tyrosine was routinely monitored and was negligible (i.e., $<5 \%$ of the level of the natural-abundance product observed) under the conditions used.

Statistical analysis. Power calculations were performed based on previously reported means and SDs of $\mathrm{NO}_{2} \mathrm{Tyr}$ and ClTyr in clinical studies. It was determined that at least 30 patients were needed in each group to have $80 \%$ power to detect a $40 \%$ difference in marker level. Data are presented as median (interquartile range), and significance level was set at $P<0.05$. The Wilcoxon rank-sum test was used to compare levels 
between groups. Logistic regression was used to obtain odds ratios by tertiles. Pearson product-moment or Spearman rank correlation coefficients were generated to assess the association among $\mathrm{NO}_{2} \mathrm{Tyr}$, ClTyr, and cholesterol efflux values. Statistical analyses were performed using SPSS version 11.0 (SPSS Inc., Chicago, Illinois, USA).

\section{Acknowledgments}

This work was supported by NIH grants P01 HL076491, HL70621, HL62526, HL077692, HL66082, and P50 HL70128 and the Cleveland Clinic Foundation General Clinical Research Center (M01 RR018390). All MS studies were performed at Mass Spectrometry Core Facilities of the Cleveland Clinic Foundation. Some of the instrumentation used in the Mass Spectrometry Core was pur- chased with grants from the NIH (RR16794, 1 S10 RR15794) and the State of Ohio Hayes Investment Fund.

Received for publication January 20, 2004, and accepted in revised form July 8, 2004.

Address correspondence to: Stanley L. Hazen, Preventive Cardiology, Cleveland Clinic Foundation, 9500 Euclid Avenue, C51, Cleveland, Ohio 44195, USA. Phone: (216) 445-9763; Fax: (216) 444-9404; E-mail: hazens@ccf.org.

Leonor Thomson's present address is: Facultad de Ciencias, Universidad de la Republica, Montevideo, Uruguay.
1. Chisolm, G.M., and Steinberg, D. 2000. The oxidative modification hypothesis of atherogenesis: an overview. Free Radic. Biol. Med. 28:1815-1826.

2. Lusis, A.J. 2000. Atherosclerosis. Nature. 407:233-241.

3. Navab, M., et al. 2002. Oxidized lipids as mediators of coronary heart disease. Curr. Opin. Lipidol. 13:363-372.

4. Podrez, E.A., Abu-Soud, H.M., and Hazen, S.L. 2000. Myeloperoxidase-generated oxidants and atherosclerosis. Free Radic. Biol. Med. 28:1717-1725.

5. Heinecke, J.W. 2003. Oxidative stress: new approaches to diagnosis and prognosis in atherosclerosis. Am. J. Cardiol. 91:12A-16A.

6. Beckman, J.S., and Koppenol, W.H. 1996. Nitric oxide, superoxide, and peroxynitrite: the good, the bad, and ugly. Am. J. Physiol. 271:C1424-C1437.

7. Beckman, J.S., Chen, J., Ischiropoulos, H., and Crow, J.P. 1994. Oxidative chemistry of peroxynitrite. Methods Enzymol. 233:229-240.

8. Leeuwenburgh, C., et al. 1997. Reactive nitrogen intermediates promote low density lipoprotein oxidation in human atherosclerotic intima. J. Biol. Chem. 272:1433-1436.

9. Podrez, E.A., Schmitt, D., Hoff, H.F., and Hazen, S.L. 1999. Myeloperoxidase-generated reactive nitrogen species convert LDL into an atherogenic form in vitro. J. Clin. Invest. 103:1547-1560.

10. Shishehbor, M.H., et al. 2003. Association of nitrotyrosine levels with cardiovascular disease and modulation by statin therapy. JAMA. 289:1675-1680.

11. Kinlay, S., Libby, P., and Ganz, P. 2001. Endothelial function and coronary artery disease. Curr. Opin. Lipidol. 12:383-389.

12. Moncada, S. 1999. Nitric oxide: discovery and impact on clinical medicine. J. R. Soc. Med. 92:164-169.

13. Ignarro, L.J., Napoli, C., and Loscalzo, J. 2002. Nitric oxide donors and cardiovascular agents modulating the bioactivity of nitric oxide: an overview. Circ. Res. 90:21-28.

14. Graham, A., et al. 1993. Peroxynitrite modification of low-density lipoprotein leads to recognition by the macrophage scavenger receptor. FEBS Lett. 330:181-185.

15. MacMillan-Crow, L.A., Crow, J.P., Kerby, J.D., Beckman, J.S., and Thompson, J.A. 1996. Nitration and inactivation of manganese superoxide dismutase in chronic rejection of human renal allografts. Proc. Natl. Acad. Sci. U. S. A. 93:11853-11858.

16. Hazen, S.L., Hsu, F.F., Gaut, J.P., Crowley, J.R., and Heinecke, J.W. 1999. Modification of proteins and lipids by myeloperoxidase. Methods Enzymol. 300:88-105.

17. Brennan, M.L., et al. 2002. A tale of two controversies: defining both the role of peroxidases in nitrotyrosine formation in vivo using eosinophil peroxidase and myeloperoxidase-deficient mice, and the nature of peroxidase-generated reactive nitrogen species. J. Biol. Chem. 277:17415-17427.

18. van der Vliet, A., Eiserich, J.P., Halliwell, B., and Cross, C.E. 1997. Formation of reactive nitrogen spe- cies during peroxidase-catalyzed oxidation of nitrite. A potential additional mechanism of nitric oxidedependent toxicity. J. Biol. Chem. 272:7617-7625.

19. Eiserich, J.P., et al. 1998. Formation of nitric oxidederived inflammatory oxidants by myeloperoxidase in neutrophils. Nature. 391:393-397.

20. Wu, W., Chen, Y., and Hazen, S.L. 1999. Eosinophil peroxidase nitrates protein tyrosyl residues. Implications for oxidative damage by nitrating intermediates in eosinophilic inflammatory disorders. J. Biol. Chem. 274:25933-25944.

21. Beckmann, J.S., et al. 1994. Extensive nitration of protein tyrosines in human atherosclerosis detected by immunohistochemistry. Biol. Chem. HoppeSeyler. 375:81-88.

22. Shishehbor, M.H., et al. 2003. Statins promote potent systemic antioxidant effects through specific inflammatory pathways. Circulation. 108:426-431.

23. Abu-Soud, H.M., and Hazen, S.L. 2000. Nitric oxide is a physiological substrate for mammalian peroxidases. J. Biol. Chem. 275:37524-37532.

24. Burner, U., Furtmuller, P.G., Kettle, A.J., Koppenol, W.H., and Obinger, C. 2000. Mechanism of reaction of myeloperoxidase with nitrite. J. Biol. Chem. 275:20597-20601.

25. Zhang, R., et al. 2002. Myeloperoxidase functions as a major enzymatic catalyst for initiation of lipid peroxidation at sites of inflammation. J. Biol. Chem. 277:46116-46122.

26. Baldus, S., et al. 2001. Endothelial transcytosis of myeloperoxidase confers specificity to vascular ECM proteins as targets of tyrosine nitration. J. Clin. Invest. 108:1759-1770. doi:10.1172/ JCI200112617.

27. Gaut, J.P., et al. 2002. Myeloperoxidase produces nitrating oxidants in vivo. J. Clin. Invest. 109:1311-1319. doi:10.1172/JCI200215021.

28. Daugherty, A., Dunn, J.L., Rateri, D.L., and Heinecke, J.W. 1994. Myeloperoxidase, a catalyst for lipoprotein oxidation, is expressed in human atherosclerotic lesions. J. Clin. Invest. 94:437-444.

29. Sugiyama, S., et al. 2001. Macrophage myeloperoxidase regulation by granulocyte macrophage colony-stimulating factor in human atherosclerosis and implications in acute coronary syndromes. Am. J. Pathol. 158:879-891.

30. Hazen, S.L., Gaut, J.P., Crowley, J.R., Hsu, F.F., and Heinecke, J.W. 2000. Elevated levels of protein-bound p-hydroxyphenylacetaldehyde, an amino-acid-derived aldehyde generated by myeloperoxidase, are present in human fatty streaks, intermediate lesions and advanced atherosclerotic lesions. Biochem. J. 3:693-699.

31. Thukkani, A.K., et al. 2003. Identification of alphachloro fatty aldehydes and unsaturated. Circulation. 108:3128-3133.

32. Zhang, R., et al. 2001. Association between myeloperoxidase levels and risk of coronary artery disease. JAMA. 286:2136-2142.

33. Brennan, M.L., et al. 2003. Prognostic value of myeloperoxidase in patients with chest pain. N. Engl. J. Med. 349:1595-1604.

34. Baldus, S., et al. 2003. Myeloperoxidase serum levels predict risk in patients with acute coronary syndromes. Circulation. 108:1440-1445.

35. Carr, A.C., Myzak, M.C., Stocker, R., McCall, M.R. and Frei, B. 2000. Myeloperoxidase binds to lowdensity lipoprotein: potential implications for atherosclerosis. FEBS Lett. 487:176-180.

36. Yang, C.Y., et al. 1999. Selective modification of apoB-100 in the oxidation of low density lipoproteins by myeloperoxidase in vitro. J. Lipid Res. 40:686-698.

37. Hazen, S.L., and Heinecke, J.W. 1997. 3-Chlorotyrosine, a specific marker of myeloperoxidase-catalyzed oxidation, is markedly elevated in low density lipoprotein isolated from human atherosclerotic intima. J. Clin. Invest. 99:2075-2081.

38. Brennan, M.L., et al. 2001. Increased atherosclerosis in myeloperoxidase-deficient mice. J. Clin. Invest. 107:419-430.

39. Zhang, Z., and Smith, D.L. 1993. Determination of amide hydrogen exchange by mass spectrometry: a new tool for protein structure elucidation. Protein Sci. 2:522-531.

40. Woods, V.L., Jr., and Hamuro, Y. 2001. High resolution, high-throughput amide deuterium exchangemass spectrometry (DXMS) determination of protein binding site structure and dynamics: utility in pharmaceutical design. J. Cell. Biochem. Suppl. 37:89-98.

41. Remaley, A.T., et al. 1997. Decreased reverse cholesterol transport from Tangier disease fibroblasts. Acceptor specificity and effect of brefeldin on lipid efflux. Arterioscler. Thromb. Vasc. Biol. 17:1813-1821.

42. Takahashi, Y., et al. 2000. Identification of cAMP analogue inducible genes in RAW264 macrophages. Biochim. Biophys. Acta. 1492:385-394.

43. Chen, W., Silver, D.L., Smith, J.D., and Tall, A.R. 2000. Scavenger receptor-BI inhibits ATP-binding cassette transporter 1-mediated cholesterol efflux in macrophages. J. Biol. Chem. 275:30794-30800.

44. Smith, J.D., et al. 1996. Cyclic AMP induces apolipoprotein E binding activity and promotes cholesterol efflux from a macrophage cell line to apolipoprotein acceptors. J. Biol. Chem. 271:30647-30655

45. Takahashi, Y., and Smith, J.D. 1999. Cholesterol efflux to apolipoprotein AI involves endocytosis and resecretion in a calcium-dependent pathway. Proc. Natl. Acad. Sci. U. S. A. 96:11358-11363.

46. Boullier, A., et al. 2001. Scavenger receptors, oxidized LDL, and atherosclerosis. Ann. N. Y. Acad. Sci. 947:214-222.

47. Navab, M., et al. 2001. HDL and the inflammatory response induced by LDL-derived oxidized phospholipids. Arterioscler. Thromb. Vasc. Biol. 21:481-488.

48. Ansell, B.J., et al. 2003. Inflammatory/antiinflammatory properties of high-density lipoprotein. Circulation. 108:2751-2756. 
49. Navab, M., et al. 2000. Normal high density lipoprotein inhibits three steps in the formation of mildly oxidized low density lipoprotein: step 1 . J. Lipid Res. 41:1481-1494.

50. Navab, M., Van Lenten, B.J., Reddy, S.T., and Fogelman, A.M. 2001. High-density lipoprotein and the dynamics of atherosclerotic lesions. Circulation. 104:2386-2387.

51. Navab, M., et al. 2001. A cell-free assay for detecting HDL that is dysfunctional in preventing the formation of or inactivating oxidized phospholipids. J. Lipid Res. 42:1308-1317.

52. Nagano, Y., Arai, H., and Kita, T. 1991. High density lipoprotein loses its effect to stimulate efflux of cholesterol from foam cells after oxidative modification. Proc. Natl. Acad. Sci. U. S. A. 88:6457-6461.

53. Panzenboeck, U., et al. 1997. Effects of reagent and enzymatically generated hypochlorite on physicochemical and metabolic properties of high density lipoproteins. J. Biol. Chem. 272:29711-29720.

54. Bergt, C., et al. 2001. Human neutrophils employ the myeloperoxidase/hydrogen peroxide/chloride system to oxidatively damage apolipoprotein A-I. Eur. J. Biochem. 268:3523-3531.

55. Graham, A., Vinogradov, D.V., and Owen, J.S. 1998. Effects of peroxynitrite on plasma components of the reverse cholesterol transport pathway. FEBS Lett. 431:327-332.

56. Wang, W.Q., Merriam, D.L., Moses, A.S., and Francis, G.A. 1998. Enhanced cholesterol efflux by tyrosyl radical-oxidized high density lipoprotein is mediated by apolipoprotein AI-AII heterodimers. J. Biol. Chem. 273:17391-17398.

57. Panzenbock, U., Kritharides, L., Raftery, M., Rye, K.A., and Stocker, R. 2000. Oxidation of methionine residues to methionine sulfoxides does not decrease potential antiatherogenic properties of apolipoprotein A-I. J. Biol. Chem. 275:19536-19544.

58. Marsche, G., et al. 2002. Hypochlorite-modified high density lipoprotein, a high affinity ligand to scavenger receptor class B, type I, impairs high density lipoprotein-dependent selective lipid uptake and reverse cholesterol transport. J. Biol. Chem. 277:32172-32179.

59. Pryor, W.A. 2000. Vitamin E and heart disease: basic science to clinical intervention trials. Free Radic. Biol. Med. 28:141-164.

60. Steinberg, D., and Witztum, J.L. 2002. Is the oxidative modification hypothesis to human atherosclerosis? Do the antioxidant trials conducted to date refute the hypothesis? Circulation. 105:2107-2111.

61. Vivekananthan, D.P., Penn, M.S., Sapp, S.K., Hsu, A., and Topol, E.J. 2003. Use of antioxidant vitamins for the prevention of cardiovascular disease: meta-analysis of randomised trials. Lancet. 361:2017-2023.

62. Hazell, L.J., and Stocker, R. 1997. Alpha-tocopherol does not inhibit hypochlorite-induced oxidation of apolipoprotein B-100 of low-density lipoprotein. FEBS Lett. 414:541-544

63. Savenkova, M.L., Mueller, D.M., and Heinecke, J.W. 1994. Tyrosyl radical generated by myeloperoxidase is a physiological catalyst for the initiation of lipid peroxidation in low density lipoprotein. J. Biol. Chem. 269:20394-20400.

64. Rubbo, H., et al. 2000. Nitric oxide reaction with lipid peroxyl radicals spares alpha-tocopherol during lipid peroxidation. Greater oxidant protec- tion from the pair nitric oxide/alpha-tocopherol than alpha-tocopherol/ascorbate. J. Biol. Chem. 275:10812-10818.

65. Upston, J.M., Terentis, A.C., and Stocker, R. 1999. Tocopherol-mediated peroxidation of lipoproteins: implications for vitamin $\mathrm{E}$ as a potential antiatherogenic supplement. FASEB J. 13:977-994.

66. Lee, S.H., Oe, T., and Blair, I.A. 2001. Vitamin Cinduced decomposition of lipid hydroperoxides to endogenous genotoxins. Science. 292:2083-2086.

67. Meagher, E.A., Barry, O.P., Lawson, J.A., Rokach, J., and FitzGerald, G.A. 2001. Effects of vitamin E on lipid peroxidation in healthy persons. JAMA. 285:1178-1182.

68. Van Lenten, B.J., Navab, M., Shih, D., Fogelman, A.M., and Lusis, A.J. 2001. The role of high-density lipoproteins in oxidation and inflammation. Trends Cardiovasc. Med. 11:155-161.

69. Nofer, J.R., et al. 2002. HDL and arteriosclerosis: beyond reverse cholesterol transport. Atherosclerosis. 161:1-16.

70. Plump, A.S., Scott, C.J., and Breslow, J.L. 1994. Human apolipoprotein A-I gene expression increases high density lipoprotein and suppresses atherosclerosis in the apolipoprotein E-deficient mouse. Proc. Natl. Acad. Sci. U. S. A. 91:9607-9611.

71. Nissen, S.E., et al. 2003. Effect of recombinant ApoA-I Milano on coronary atherosclerosis in patients with acute coronary syndromes: a randomized controlled trial. JAMA. 290:2292-2300.

72. Francis, G.A., Knopp, R.H., and Oram, J.F. 1995 Defective removal of cellular cholesterol and phospholipids by apolipoprotein A-I in Tangier disease. J. Clin. Invest. 96:78-87.

73. Brooks-Wilson, A., et al. 1999. Mutations in ABC1 in Tangier disease and familial high-density lipoprotein deficiency. Nat. Genet. 22:336-345.

74. Bodzioch, M., et al. 1999. The gene encoding ATPbinding cassette transporter 1 is mutated in Tangier disease. Nat. Genet. 22:347-351.

75. Rust, S., et al. 1999. Tangier disease is caused by mutations in the gene encoding ATP-binding cassette transporter 1. Nat. Genet. 22:352-355.

76. Lawn, R.M., et al. 1999. The Tangier disease gene product $\mathrm{ABC} 1$ controls the cellular apolipoproteinmediated lipid removal pathway. J. Clin. Invest. 104:25-31.

77. Singaraja, R.R., et al. 2002. Increased ABCA1 activity protects against atherosclerosis. J. Clin. Invest. 110:35-42. doi:10.1172/JCI200215748.

78. Aiello, R.J., et al. 2002. Increased atherosclerosis in hyperlipidemic mice with inactivation of ABCA1 in macrophages. Arterioscler. Thromb. Vasc. Biol. 22:630-637.

79. Kutter, D., et al. 2000. Consequences of total and subtotal myeloperoxidase deficiency: risk or benefit? Acta Haematol. 104:10-15

80. Nikpoor, B., Turecki, G., Fournier, C., Theroux, P., and Rouleau, G.A. 2001. A functional myeloperoxidase polymorphic variant is associated with coronary artery disease in French-Canadians. Am. Heart J. 142:336-339.

81. Pecoits-Filho, R., et al. 2003. A functional variant of the myeloperoxidase gene is associated with cardiovascular disease in end-stage renal disease patients. Kidney Int. Suppl. 84:172-176.

82. Asselbergs, F.W., Reynolds, W.F., Cohen-Tervaert, J.W., Jessurun, G.A., and Tio, R.A. 2004
Myeloperoxidase polymorphism related to cardiovascular events in coronary artery disease. Am. J. Med. 116:429-430.

83. Vita, J.A., et al. 2004. Serum myeloperoxidase levels independently predict endothelial dysfunction: in vivo support that myeloperoxidase acts as a catalytic sink for nitric oxide. Circulation. In press.

84. Markwell, M.A., Haas, S.M., Bieber, L.L., and Tolbert, N.E. 1978. A modification of the Lowry procedure to simplify protein determination in membrane and lipoprotein samples. Anal. Biochem. 87:206-210.

85. Nelson, D.P., and Kiesow, L.A. 1972. Enthalpy of decomposition of hydrogen peroxide by catalase at 25 degrees $\mathrm{C}$ (with molar extinction coefficients of $\mathrm{H} 2 \mathrm{O} 2$ solutions in the UV). Anal. Biochem. 49:474-478.

86. Rakita, R.M., Michel, B.R., and Rosen, H. 1990. Differential inactivation of Escherichia coli membrane dehydrogenases by a myeloperoxidase-mediated antimicrobial system. Biochemistry. 29:1075-1080.

87. Wever, R., Plat, H., and Hamers, M.N. 1981. Human eosinophil peroxidase: a novel isolation procedure, spectral properties and chlorinating activity. FEBS Lett. 123:327-331.

88. van Dalen, C.J., Whitehouse, M.W., Winterbourn, C.C., and Kettle, A.J. 1997. Thiocyanate and chloride as competing substrates for myeloperoxidase. Biochem. J. 327:487-492.

89. Agner, K. 1972. Biological effects of hyperchlorous acid formed by "MPO" peroxidation in the presence of chloride ions. In Structure and function of oxidation-reduction enzymes. 1st edition. A. Akeson and A. Ehrenberg, editors. Pergamon Press. Tarrytown, New York, USA. 329-335.

90. Hatch, F.T. 1968. Practical methods for plasma lipoprotein analysis. Adv. Lipid Res. 6:1-68.

91. Goldstein, J.L., Ho, Y.K., Basu, S.K., and Brown, M.S. 1979. Binding site on macrophages that mediates uptake and degradation of acetylated low density lipoprotein, producing massive cholesterol deposition. Proc. Natl. Acad. Sci. U. S. A. 76:333-337.

92. MacPherson, J.C., et al. 2001. Eosinophils are a major source of nitric oxide-derived oxidants in severe asthma: characterization of pathways available to eosinophils for generating reactive nitrogen species. J. Immunol. 166:5763-5772.

93. Steinbrecher, U.P., and Lougheed, M. 1992. Scavenger receptor-independent stimulation of cholesterol esterification in macrophages by low density lipoprotein extracted from human aortic intima. Arterioscler. Thromb. 12:608-625.

94. Krul, E.S., Tang, J., Kettler, T.S., Clouse, R.E., and Schonfeld, G. 1992. Lengths of truncated forms of apolipoprotein B (apoB) determine their intestinal production. Biochem. Biophys. Res. Commun. 189:1069-1076.

95. Laemmli, U.K. 1970. Cleavage of structural proteins during the assembly of the head of bacteriophage T4. Nature. 227:680-685.

96. Kinter, M., and Sherman, N. 2000. Protein sequencing and identification using tandem mass spectrometry. John Wiley \& Sons Inc. New York, New York, USA. 166-206.

97. Willard, B.B., Ruse, C.I., Keightley, J.A., Bond, M., and Kinter, M. 2003. Site-specific quantitation of protein nitration using liquid chromatography/tandem mass spectrometry. Anal. Chem. 75:2370-2376. 